\title{
Regulation of Angiogenic Functions by Angiopoietins through Calcium-Dependent Signaling Pathways
}

\author{
Irene Pafumi, ${ }^{1}$ Annarita Favia, ${ }^{1}$ Guido Gambara, ${ }^{1,2}$ Francesca Papacci, ${ }^{1}$ Elio Ziparo, ${ }^{1}$ \\ Fioretta Palombi, ${ }^{1}$ and Antonio Filippini ${ }^{1}$ \\ ${ }^{1}$ Department of Anatomy, Histology, Forensic Medicine and Orthopaedics, Unit of Histology and Medical Embryology, \\ Sapienza University of Rome, 00161 Rome, Italy \\ ${ }^{2}$ Institute of Vegetative Anatomy, Charité Universitätsmedizin, Neuromuscular Group, 10115 Berlin, Germany
}

Correspondence should be addressed to Antonio Filippini; antonio.filippini@uniromal.it

Received 19 December 2014; Revised 12 February 2015; Accepted 15 February 2015

Academic Editor: Jie-Hui Li

Copyright (C) 2015 Irene Pafumi et al. This is an open access article distributed under the Creative Commons Attribution License, which permits unrestricted use, distribution, and reproduction in any medium, provided the original work is properly cited.

\begin{abstract}
Angiopoietins are vascular factors essential for blood vessel assembly and correct organization and maturation. This study describes a novel calcium-dependent machinery activated through Angiopoietin-1/2-Tie receptor system in HUVECs monolayer. Both cytokines were found to elicit intracellular calcium mobilization. Targeting intracellular $\mathrm{Ca}^{2+}$ signaling, antagonizing $\mathrm{IP}_{3}$ with 2$\mathrm{APB}$ or $\mathrm{CADPR}$ with $8 \mathrm{Br}-\mathrm{cADPR}$, was found to modulate in vitro angiogenic responses to Angiopoietins in a specific way. 2-APB and $8 \mathrm{Br}-\mathrm{cADPR}$ impaired the phosphorylation of AKT and FAK induced by Ang-1 and Ang-2. On the other hand, phosphorylation of ERK1/2 and p38, as well as cell proliferation, was not affected by either inhibitor. The ability of ECs to migrate following Angs stimulation, evaluated by "scratch assay," was reduced by either 2-APB or 8Br-cADPR following Ang-2 stimulation and only slightly affected by 2 -APB in cells stimulated with Ang-1. These results identify a novel calcium-dependent machinery involved in the complex interplay regulating angiogenic processes showing that $\mathrm{IP}_{3}$ - and $\mathrm{cADPR}$-induced $\mathrm{Ca}^{2+}$ release specifically regulates distinct Angs-mediated angiogenic steps.
\end{abstract}

\section{Introduction}

Angiogenesis is a complex remodeling process characterized by the sprouting of new blood vessels from preexisting ones, occurring mainly during embryonic development and in pathological processes such as cancer. During the early stages of this process, endothelial cells (ECs) are stimulated to form new capillaries by growth factors such as vascular endothelial growth factor (VEGF) and fibroblast growth factor (FGF). Angiopoietins (Angs) play a fundamental role in the subsequent maturation step, in which microvessels acquire a layer of mural cells, pericytes, and smooth muscle cells, which are critical for the development and maintenance of functional vasculature $[1,2]$. Experimental evidence identifies the Angs and their Tie receptors as important regulators of tumorinduced angiogenesis and metastasis $[3,4]$. So far, a major effort in the field of angiogenesis control has centered on the VEGF-VEGF receptor system $[5,6]$. However, despite partial success, resistance to anti-VEGF therapy, resulting from a variety of mechanisms, remains a major obstacle [79]. The search for novel key downstream effectors as a possible common "signaling hub" between Angs and other known growth factors is therefore of potential significance in the perspective of angiogenesis control in cancer.

The Tie receptors and their Angiopoietin (Ang) ligands have been identified as the second vascular tissue-specific tyrosine kinase receptor system. Angs-Tie system is essential during embryonic vessel assembly and for the correct organization and maturation of newly formed vessels and functions as a key regulator of adult vascular homeostasis in the later stages of the angiogenic cascade. Thus, whereas VEGF signals promote initiating events in angiogenesis, such as ECs sprouting and proliferation, Ang-Tie signals appear to promote ECs survival and vascular assembly, stability, and maturation [10]. The best-characterized Angs are Angiopoietin-1 (Ang-1) and Angiopoietin-2 (Ang-2), 
which are secreted glycoproteins with a dimeric structure and molecular weight of approximately $75 \mathrm{kDa}$ [11] showing about $60 \%$ amino acid sequence homology. Ang-1 is expressed by smooth muscle cells and other perivascular cells and acts in a paracrine manner as agonist of the endothelial Tie2 receptor, whereas Ang-2 is considered as its antagonist although also reported to context-dependently act as a Tie2 agonist inducing receptor phosphorylation [12-14]. The molecular basis for agonistic versus antagonistic functions of Ang-2 has not been unraveled. Cell type specific effects, the degree of endothelial confluence, the duration of Ang-2 stimulation, concentration dependent effects, and the presence of the coreceptors such as Tie-1 have all been implicated in controlling agonistic versus antagonistic function of Ang2 [15-18]. Ang-1 induces tyrosine phosphorylation of Tie-2 in ECs and activates downstream signaling pathways such as mitogen-activated protein kinase (MAPK) pathways. In adult tissues, Ang-1 does not induce endothelial chemotaxis or proliferation but exerts a dual role: it stimulates angiogenesis at sites of vascular remodeling contributing to the formation of capillary sprouts, while it stimulates prosurvival pathways and promotes vascular quiescence in mature vessels, preventing apoptosis and inflammation through the activation of PI3K-AKT and MAPK/ERK signaling pathways [19-21]. Ang-2 is almost exclusively expressed by ECs where it is stored in Weibel-Palade bodies (WPB) [22, 23]. Following cytokine activation of the endothelium, Ang-2 is rapidly released and acts in an autocrine manner on Tie- 2 receptor binding as homodimers or multimers. Under physiological conditions, in the adult tissues Ang-2 is expressed in regions of vascular remodelling, during vascularization of the retina or during vessel formation/regression of ovarian corpus luteum. Ang-2 expression is also upregulated under pathological conditions, for example, in the endothelium of tumors [24-26]. Interestingly, experimental evidence indicates that signaling downstream of Tie-2 activation is influenced by the subcellular localization of the receptor, which is different in confluent versus sparse ECs $[1,27]$. In these studies, Ang-1 produced stronger AKT signaling in confluent cells, in which Tie-2 was localized at cell/cell junctions, and stronger ERK activation when cells were sparse and Tie-2 was localized at cell/matrix junction, indicating that the effect of Ang-1 on Tie-2 activation may depend on the nature of cell/cell or cell/matrix contacts. Less well known is the role of calcium $\left(\mathrm{Ca}^{2+}\right)$ in the regulation of angiogenic processes. $\mathrm{Ca}^{2+}$ is a crucial point of intersection for many distinct molecular signaling pathways that promote and modulate angiogenesis. Specific $\mathrm{Ca}^{2+}$ signatures rely upon spatiotemporal variations in $\left[\mathrm{Ca}^{2+}\right]_{\mathrm{i}}$ [28] and are mainly based on three second messengers, namely, inositol trisphosphate $\left(\mathrm{IP}_{3}\right)$ and cyclic adenosine diphosphoribose (cADPR), which mobilize $\mathrm{Ca}^{2+}$ from endoplasmic reticulum (ER) stores, and nicotinic acid adenine-dinucleotide phosphate (NAADP), which triggers $\mathrm{Ca}^{2+}$ release from acidic organelles $[29,30]$. We have previously demonstrated that histamine $\mathrm{H} 1$ receptors mediate NAADP-dependent $\mathrm{Ca}^{2+}$ signaling in ECs [31] and have recently identified that in HUVECs (human umbilical vein endothelial cells) VEGF increases $\left[\mathrm{Ca}^{2+}\right]_{\mathrm{i}}$ by mobilizing $\mathrm{Ca}^{2+}$ from internal stores. The latter study demonstrated the direct role of NAADP in VEGF-induced $\mathrm{Ca}^{2+}$ mobilization from acidic organelles and its important involvement in the control of angiogenic processes [32]. To our knowledge, the role of $\mathrm{Ca}^{2+}$ signaling in the regulation of Ang-1/Ang-2-induced angiogenesis has not been investigated yet. In the present work, we identify a novel pathway for Angs-Tie signaling whereby receptor activation leads to $\mathrm{IP}_{3^{-}}$and cADPRdependent $\mathrm{Ca}^{2+}$ release and show that each of these $\mathrm{Ca}^{2+}$ mobilizing second messengers specifically controls distinct Angs-mediated angiogenic steps.

\section{Materials and Methods}

2.1. Cell Culture. Human umbilical vein endothelial cells (HUVECs) were obtained from Lonza Sales Ltd., cultured in EGM-2 Endothelial Cell Growth Medium-2 (Endothelial Basal Medium EBM-2 + EGM-2 Bullet Kit, Lonza), + 100 mM penicillin/streptomycin (Sigma). Cells were maintained at $37^{\circ} \mathrm{C}$ in a humified $5 \%$ (vol/vol) incubator and grown to reach the confluence. Monolayers were used at passages 1 to 6 .

2.2. Calcium Imaging. Cells were incubated in EGM-2 containing $3.5 \mu \mathrm{M}$ Fura-2-AM (Invitrogen) for $1 \mathrm{~h}$ at $37^{\circ} \mathrm{C}$ and then rinsed with Hanks' Balanced Salt Solution (HBSS Sigma) or Krebs-Henseleit-HEPES (KHH) buffer $(140 \mathrm{mM}$ $\mathrm{Na}^{+}, 5.3 \mathrm{mM} \mathrm{K}^{+}, 132.4 \mathrm{mM} \mathrm{Cl}^{-}, 0.98 \mathrm{mM} \mathrm{PO}_{4}{ }^{2-}, 1.25 \mathrm{mM}$ $\mathrm{Ca}^{2+}, 0.81 \mathrm{mM} \mathrm{Mg}^{2+}, 5.5 \mathrm{mM}$ glucose, and $20 \mathrm{mM}$ HEPES). Plates were placed into a culture chamber kept at $37^{\circ} \mathrm{C}$ controlled temperature on the stage of an inverted microfluorimeter (Nikon TE2000E) connected to a cooled CCD camera (512B Cascade, Princeton Instruments). Samples were illuminated alternately at 340 and $380 \mathrm{~nm}$ using a random access monochromator (Photon Technology International) and emission was detected using a $510 \mathrm{~nm}$ emission filter. Images were acquired ( 1 image/sec ratio) using MetaFluor software (Universal Imaging Corporation). Calibration of the signal was obtained at the end of each experiment by maximally increasing intracellular $\mathrm{Ca}^{2+}$-dependent Fura-2-AM fluorescence with $5 \mu \mathrm{M}$ ionomycin (ionomycin calcium salt from Streptomyces conglobatus, Sigma) followed by recording minimal fluorescence in $\mathrm{Ca}^{2+}$-free medium. $\left[\mathrm{Ca}^{2+}\right]_{\mathrm{i}}$ was calculated according to previously described formulas [33].

2.3. Western Blot. Cells were first starved in EBM-2 for $4 \mathrm{~h}$ and then incubated with BAPTA-AM (Sigma, $20 \mu \mathrm{M}$ ), 2-APB (Sigma $75 \mu \mathrm{M}$ ), or $8 \mathrm{Br}-\mathrm{cADPR}$ (Sigma $30 \mu \mathrm{M}$ ) for $30 \mathrm{~min}$ before stimulation for $20 \mathrm{~min}$ with $100 \mathrm{ng} / \mathrm{mL}$ Angiopoietin1 or $200 \mathrm{ng} / \mathrm{mL}$ Angiopoietin-2 (PeproTech). Cells were washed with cold PBS before adding lysis buffer 10X (Cell Signaling), PI, and PMSF (Sigma $1 \mathrm{mM}$ ). After determining protein concentration by a BCA kit (Thermo Scientific), $25 \mu \mathrm{g}-35 \mu \mathrm{g}$ protein of each sample was loaded on $8 \%-10 \%$ SDS-PAGE. The proteins were subsequently blotted onto a nitrocellulose membrane and the membrane treated with a blocking solution TTBS $+5 \%$ milk (ECL prime blocking agent, GE Healthcare). The following primary antibodies were used: Phospho-p42/44 MAPK (T202/Y204: E10, Cell 
Signaling, 1:1,000), Phospho-AKT (Ser-473, Cell Signaling, 1:1,000), Phospho-FAK (Tyr925, Cell Signaling, 1:1,000), Phospho-p38 MAP Kinase (Thr180/Tyr182, Cell Signaling, 1:1,000), AKT (Cell Signaling, $1: 1,000$ ), ERK 2 (Santa Cruz, $1: 1,000$ ), p38 (Santa Cruz, 1:1,000), and FAK (Cell Signaling, $1: 1,000)$. All the antibodies were diluted in TTBS 5\% BSA. After three washes in TTBS, the membrane was incubated with a secondary HRP-conjugated stabilized goat anti-mouse (Pierce, $1: 10,000$ ) and stabilized peroxidase-conjugated polyclonal goat anti-rabbit (Bio-Rad, $1: 10,000) 1 \mathrm{~h}$ at RT. To ensure equal loading membranes were reprobed with monoclonal HRP-conjugated anti- $\beta$-actin (Sigma). The intensity of Western blot bands was quantified by Image J software from at least three independent experiments, normalized to both total amount of the protein indicated and $\beta$-actin content, and compared with control (vehicle) set as 1 .

2.4. Scratch Assay. Confluent ECs monolayers plated in $35 \mathrm{~mm}$ dishes were scraped along a straight line with a p10 pipette tip to create a narrow gap (scratch). The scratch created was of similar size in the different experimental conditions to minimize any possible variation caused by differences in the width. Debris were removed by a wash with PBS prior to incubation in fresh medium containing Angs in the presence or absence of inhibitors. To record cell migration, images of the wound were acquired at time zero and again $24 \mathrm{~h}$ later in an inverted microscope (Nikon Eclipse TS100) equipped with a digital camera (Nikon Ds Fi2, Nis elements F 4.00.00 software). Five random microscopic fields along each wound were photographed.

2.5. In Vitro Matrigel Assay. Capillary-like endothelial tube formation was evaluated by an angiogenesis in vitro angiogenesis assay. $130 \mu \mathrm{L}$ Matrigel basement membrane matrix growth factor reduced (BD Biosciences) was added to each well of precooled 24-well tissue culture plates. Pipette tips and Matrigel solution were kept cold during the procedure to avoid solidification. The plates were incubated for $1 \mathrm{~h}$ at $37^{\circ} \mathrm{C}$ to allow matrix solution to solidify. $4 \times 10^{4}$ cells in a final volume of $500 \mu \mathrm{L}$ EBM-2 were seeded onto the surface of each well containing the polymerized matrix. Cells were pretreated with the pharmacological inhibitors indicated or with vehicle alone and stimulated with the specific agonists $100 \mathrm{ng} / \mathrm{mL}$ Ang-1 or $200 \mathrm{ng} / \mathrm{mL}$ Ang-2 for $4-5$ hours at $37^{\circ} \mathrm{C}$. Tube formation was inspected under an inverted microscope (Nikon Eclipse TS100) at 20x magnification and images were acquired by a digital camera (Nikon Ds Fi2, Nis elements F 4.00.00 software). The closed polygons formed in five random microscopic fields per well were counted and values averaged.

2.6. Statistical Analysis. Data are presented as the mean \pm s.e.m. resulting from at least three independent experiments. Student's $t$-test was used for statistical comparison between means where applicable. Consider ${ }^{*} P<0.05,{ }^{* *} P<0.01$, and ${ }^{* * *} P<0.001$. Statistical analysis of the data in Figures 1(a) and 1(b) was performed using the one-way ANOVA test. Consider ${ }^{* * * *} P$ value $<0.0001,{ }^{*} P$ value $<0.05$. Bands on Western blots were quantified by densitometric scanning of films from three or more independent experiments.

\section{Results and Discussion}

3.1. Ang-1 and Ang-2 Mobilize Calcium from Intracellular Calcium Stores. In the present study, the involvement of $\mathrm{Ca}^{2+}$ in the signaling of Angs was tested and analysed to investigate in ECs if $\mathrm{Ca}^{2+}$ is involved in responses to Angs. We performed $\mathrm{Ca}^{2+}$ imaging experiments in HUVECs monolayer using microfluorimetric analysis. First, we performed dose response experiments stimulating Fura-2-AM-loaded HUVECs with Angs at different concentrations $(5 \mathrm{ng} / \mathrm{mL}-$ $400 \mathrm{ng} / \mathrm{mL}$ ) using HBSS buffer that allows $\mathrm{Ca}^{2+}$ entry from the extracellular environment. The maximum increase in intracellular $\mathrm{Ca}^{2+}$ concentration was found to take place at the concentration of $100 \mathrm{ng} / \mathrm{mL}$ for Ang-1 and $200 \mathrm{ng} / \mathrm{mL}$ for Ang-2 (Figures 1(a) and 1(b)). These two concentrations were therefore used in all the subsequent experiments. In order to investigate the involvement of extracellular $\mathrm{Ca}^{2+}$ influx, we performed $\mathrm{Ca}^{2+}$ imaging experiments in Ang-1/Ang-2stimulated cells using Krebs-Henseleit-HEPES buffer $(\mathrm{KHH})$ and a $\mathrm{Ca}^{2+}$-free buffer containing the extracellular $\mathrm{Ca}^{2+}$ chelator EGTA (Figures $1(\mathrm{cl})$ and 1(d1)). Representative $\left[\mathrm{Ca}^{2+}\right]_{\mathrm{i}}$ profiles are shown in Figures $1(\mathrm{c} 2)$ and $1(\mathrm{~d} 2)$. The response to Angs was found to be buffer-independent, indicating the involvement of intracellular stores. Taken together, these data show for the first time that Angs stimulation triggers intracellular $\mathrm{Ca}^{2+}$ signaling. The substantially equal values observed in presence or absence of extracellular $\mathrm{Ca}^{2+}$ prompted us to evaluate the involvement of different intracellular compartments in Angs-induced intracellular $\mathrm{Ca}^{2+}$ mobilization. We adopted a pharmacological approach using bafilomycin $\mathrm{Al}$, which inhibits $\mathrm{pH}$-dependent $\mathrm{Ca}^{2+}$ uptake into acidic stores by inhibition of the vacuolar-type $\mathrm{H}^{+}$ATPase pump, and thapsigargin, which inhibits ER SERCA pumps [29]. Angs-induced $\mathrm{Ca}^{2+}$ release was significantly impaired by thapsigargin (Figures 2(a) and 2(c)) but not by bafilomycin A1 (Figures 2(b) and 2(d)), demonstrating that $\mathrm{Ca}^{2+}$ stores different from acidic compartments are involved in this process.

3.2. Both $C A D P R$ and $I P_{3}$ Are Involved in $\left[\mathrm{Ca}^{2+}\right]_{i}$ Increase Induced by Ang-1 and Ang-2. Many cell stimuli act on receptors that are coupled to phospholipase C (PLC) that hydrolyses phosphatidylinositol 4,5-bisphosphate $\left(\mathrm{PIP}_{2}\right)$ producing $\mathrm{IP}_{3}$, in turn recognised by receptors located on the ER resulting in the release of $\mathrm{Ca}^{2+}$. The spatially and temporally organized pattern of $\mathrm{Ca}^{2+}$ release is a remarkably versatile signaling system controlling a multitude of processes in many different cell types [34]. Another $\mathrm{Ca}^{2+}$ mobilizing messenger, unrelated to $\mathrm{IP}_{3}$, has been identified as cyclic ADP-ribose (cADPR) which activates the ryanodine receptors (RyRs) in the sarco/ER [28]. To explore the involvement of these two different second messengers responsible for Ang-1and Ang-2-dependent intracellular $\mathrm{Ca}^{2+}$ mobilization from ER stores, a pharmacological approach was adopted using inhibitors specifically targeting either of them at different levels. The involvement of $\mathrm{IP}_{3}$ was studied through $\mathrm{Ca}^{2+}$ imaging experiments in cells pretreated for $20 \mathrm{~min}$ with $2 \mu \mathrm{M}$ 


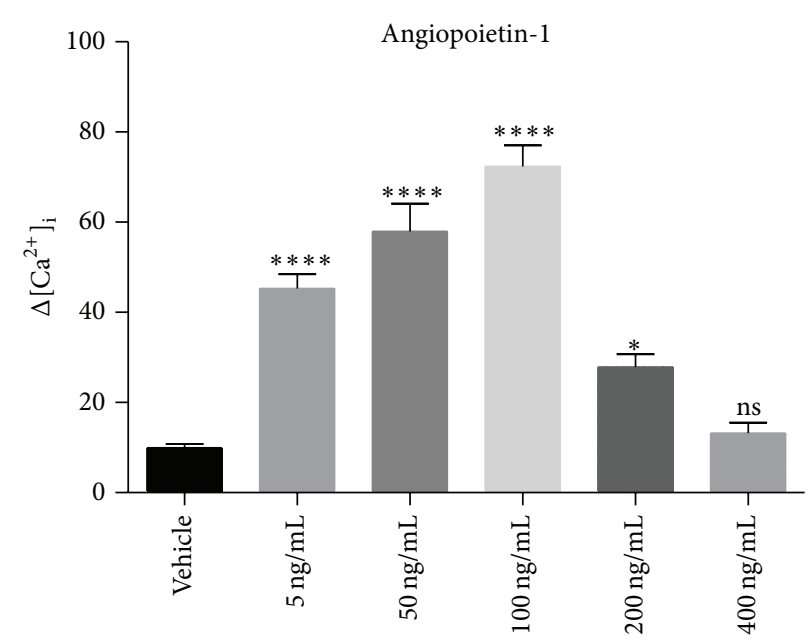

(a)

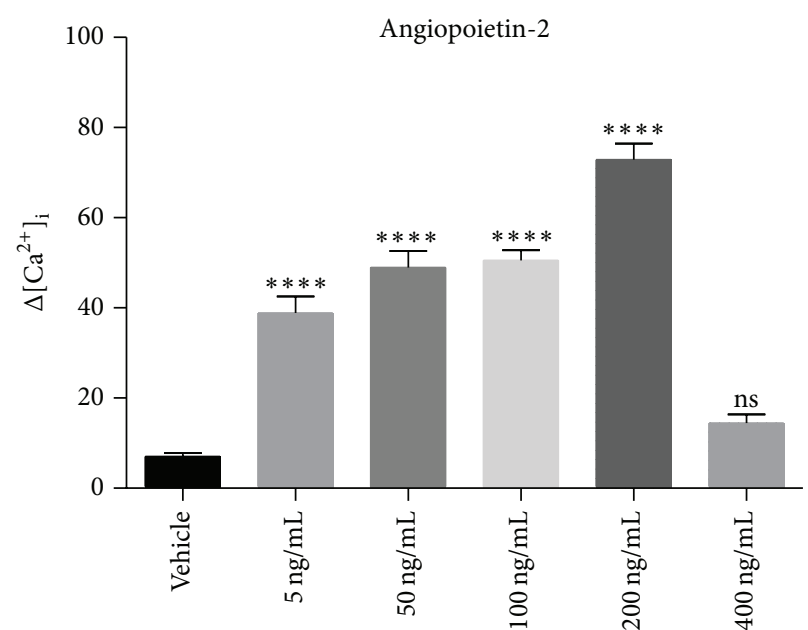

(b)

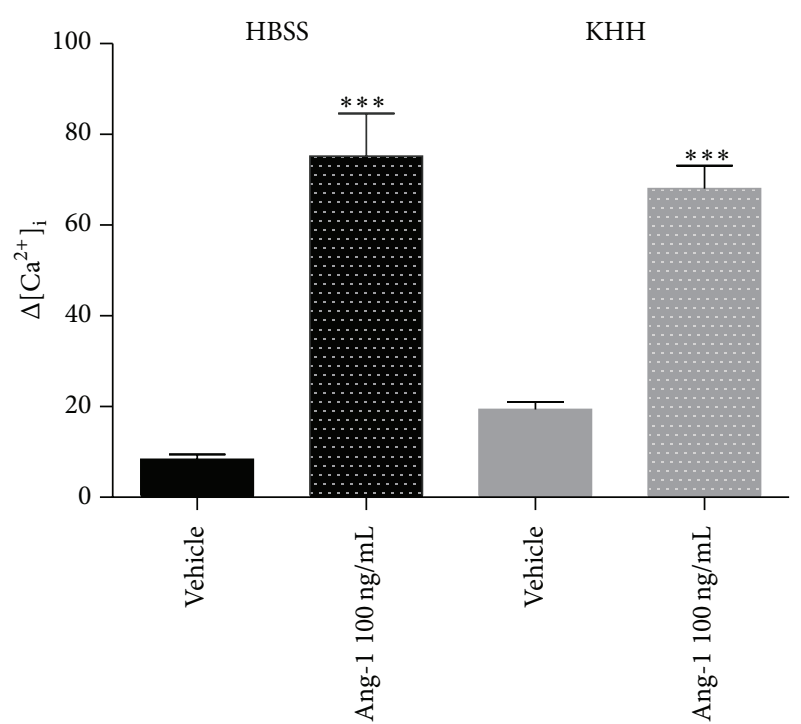

(c1)
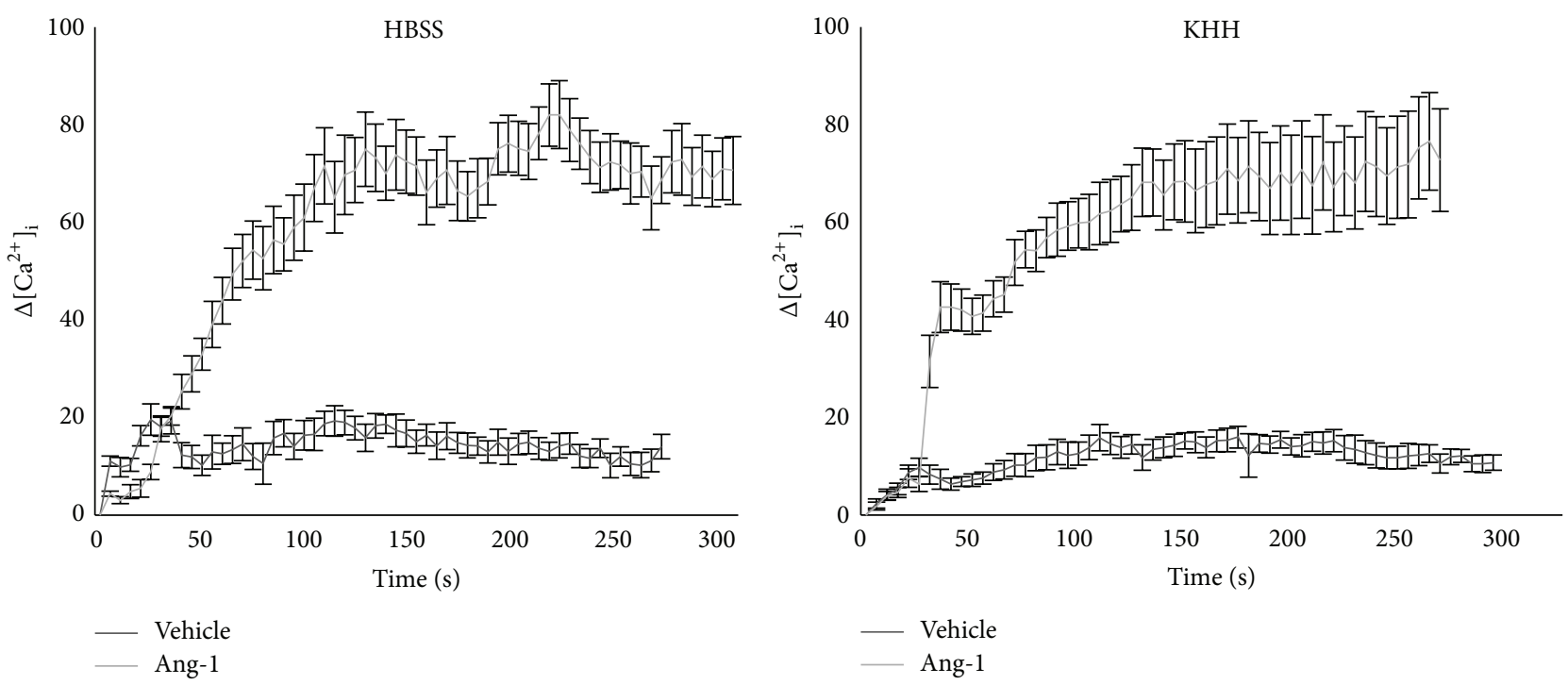

(c2)

(c) 

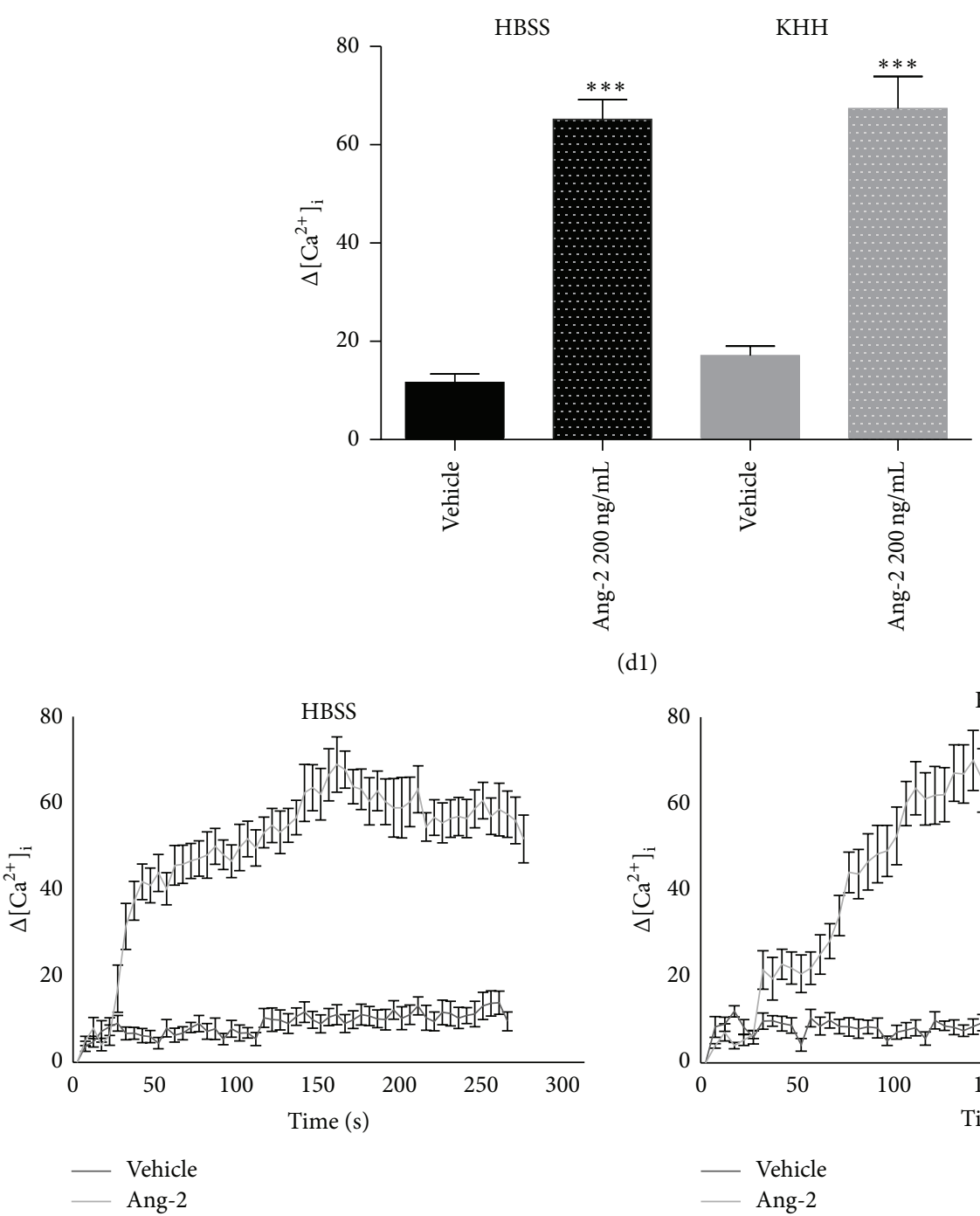

$(\mathrm{d} 1)$

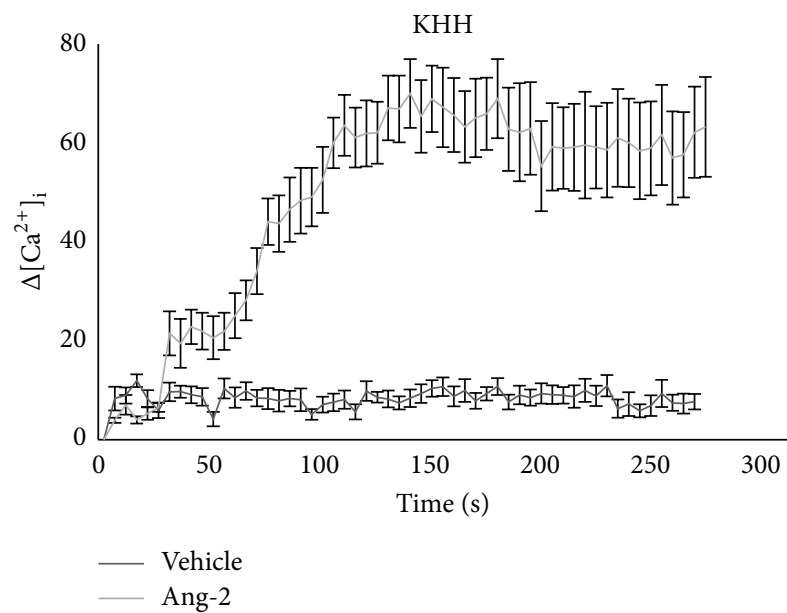

(d2)

(d)

Figure 1: $\left[\mathrm{Ca}^{2+}\right]_{\mathrm{i}}$ is increased by Ang-1 and Ang-2 stimulation. Live imaging in Fura-2-AM-loaded single cells. $\left[\mathrm{Ca}^{2+}\right]_{\mathrm{i}}$ increases (nM) following stimulation with either Ang-1 or Ang-2 at different concentrations ( 5 to $400 \mathrm{ng} / \mathrm{mL}$ ) in Ca ${ }^{2+}$ containing HBSS buffer. Identification of $100 \mathrm{ng} / \mathrm{mL}$ Ang-1 and $200 \mathrm{ng} / \mathrm{mL}$ Ang-2 as agonist concentrations is most effective in increasing $\left[\mathrm{Ca}^{2+}\right]_{\mathrm{i}}$ levels $(\mathrm{a}, \mathrm{b})$. Data in bar charts represent mean \pm s.e.m. from three independent experiments. Statistical analysis of the data was performed using one-way ANOVA test. ${ }^{* * * * *} P$ value $<0.0001,{ }^{*} P$ value $<0.05$. Lack of contribution from $\mathrm{Ca}^{2+}$ influx, tested in absence or presence of extracellular calcium (resp., in KHH or HBSS buffer) $(c, d)$. Changes in $\left[\mathrm{Ca}^{2+}\right]_{\mathrm{i}}$ levels $(\mathrm{nM})$ are shown as maximum concentration in bar charts (cl, d1) and as representative traces (c2, d2) in cells stimulated with Ang-1 or Ang-2, at the respective maximal concentrations, or with vehicle alone. Agonist-stimulated $\left[\mathrm{Ca}^{2+}\right]_{\mathrm{i}}$ increases are substantially the same in the presence or absence of extracellular $\mathrm{Ca}^{2+}$. Data in bar charts represent mean \pm s.e.m. from three independent experiments. Cell number $=78-155 .{ }^{* * *} P<0.001$ versus vehicle by Student's $t$-test. $\left[\mathrm{Ca}^{2+}\right]_{\mathrm{i}}$ values in representative traces are expressed as increase with respect to basal $\mathrm{Ca}^{2+}$ concentrations $(\Delta)$.

U73122, the antagonist of PLC, or U73343, its nonfunctional analogue, and in cells pretreated for $30 \mathrm{~min}$ with $75 \mu \mathrm{M} 2$ $\mathrm{APB}$, the selective antagonist of $\mathrm{IP}_{3}$ receptor, and stimulated with $10 \mu \mathrm{M}$ ATP as positive control or Ang-1 or Ang-2. Pretreatment with either inhibitor significantly impaired Ang-1- and Ang-2-induced $\mathrm{Ca}^{2+}$ release (Figures 3(a3), 3(a5), 3(b3), and 3(b5)) and, as expected, blocked ATP-evoked $\mathrm{Ca}^{2+}$ mobilization, known to be dependent by $\mathrm{IP}_{3}$ (Figures $3(\mathrm{al}$ ) and 3(b1)). Representative $\left[\mathrm{Ca}^{2+}\right]_{\mathrm{i}}$ traces are shown in Figures 3(a2), 3(a4), 3(a6), 3(b2), 3(b4), and 3(b6).

To identify the possible involvement of cADPR, $\mathrm{Ca}^{2+}$ imaging experiments were performed on cells pretreated for 30 min with $30 \mu \mathrm{M} 8 \mathrm{Br}-\mathrm{cADPR}$, the cell permeant antagonist of cADPR, that binds ER RyRs and then stimulated with Ang-1 or Ang-2. As shown in Figure 4, intracellular $\mathrm{Ca}^{2+}$ release after stimulation with either Ang was significantly 


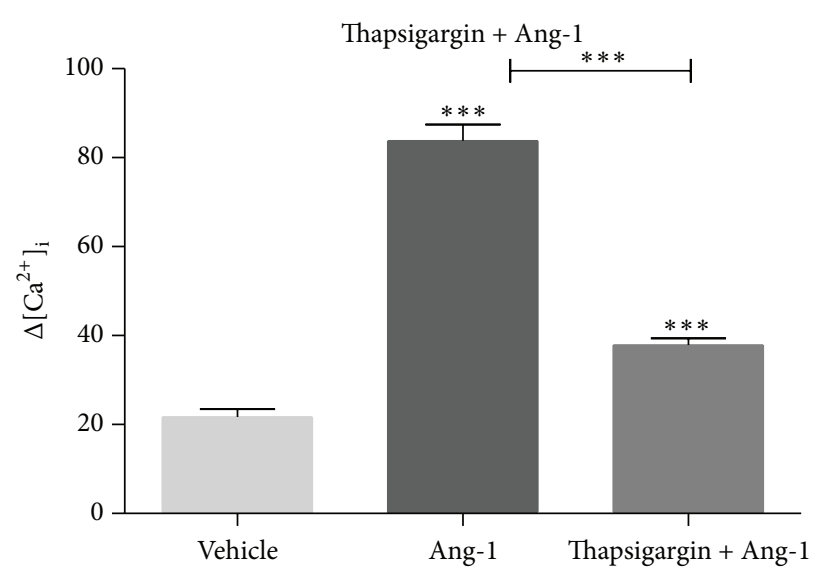

(a)

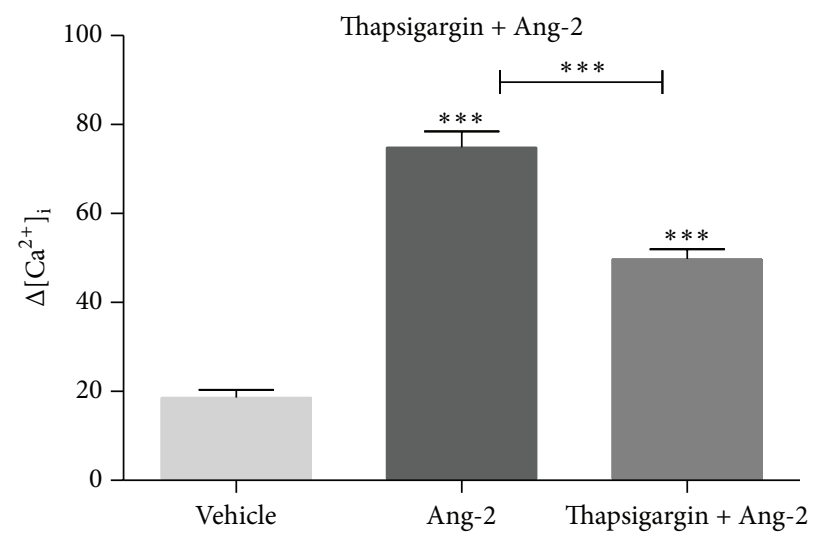

(c)

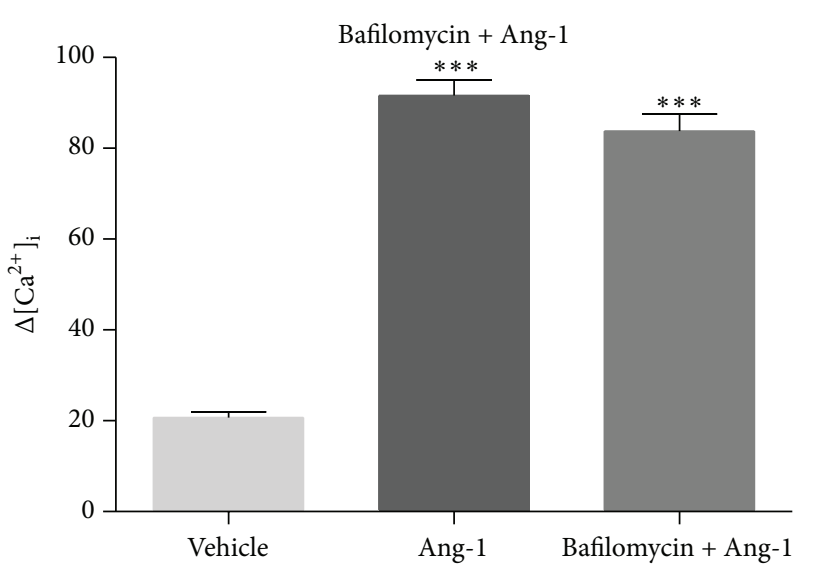

(b)

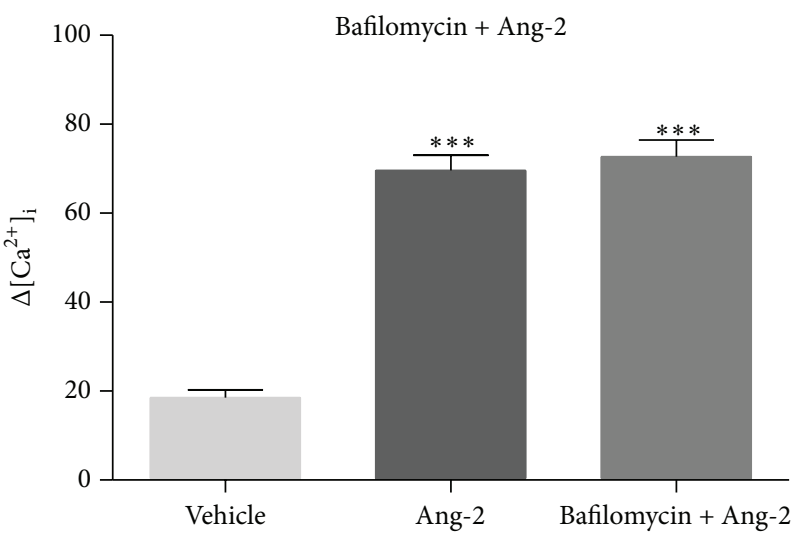

(d)

FIGURE 2: Ang-1 and Ang-2 mobilize $\left[\mathrm{Ca}^{2+}\right]_{\mathrm{i}}$ from ER but not from acidic stores. Live imaging in Fura-2-AM-loaded single cells. Identification of Ang-1- and Ang-2-activated $\left[\mathrm{Ca}^{2+}\right]_{\mathrm{i}}$ stores. Histograms represent $\mathrm{Ca}^{2+}$ release in cells stimulated with $100 \mathrm{ng} / \mathrm{mL}$ Ang-1 or $200 \mathrm{ng} / \mathrm{mL}$ Ang2 after pretreatment with vehicle alone, or with $1 \mu \mathrm{M}$ thapsigargin for $15 \mathrm{~min}(\mathrm{a}, \mathrm{c})$, or with $500 \mathrm{nM}$ bafilomycin $\mathrm{Al}$ for $1 \mathrm{~h}$ in Ca ${ }^{2+}$-free medium $\mathrm{KHH}(\mathrm{b}, \mathrm{d}) . \Delta$ on the $y$-axes $=\mathrm{nM}$. Data in bar charts represent mean \pm s.e.m. from three independent experiments. Cell number $=68-187$. ${ }^{* * *} P<0.001$ by Student's $t$-test.

reduced in cells pretreated with this inhibitor (Figures 4(a1) and 4(a3)). Representative $\left[\mathrm{Ca}^{2+}\right]_{\mathrm{i}}$ traces are shown in Figures 4(a2) and 4(a4). These observations demonstrate that Angs mobilize $\mathrm{Ca}^{2+}$ from ER stores through $\mathrm{IP}_{3}$ and cADPR signaling and that the involvement of either pathway is Ang-1/2 isoform specific. In particular, the unexpected partial insensitivity to thapsigargin, U73122, 2-APB, and 8BrcADPR, observed with Ang-2 stimulation, suggests that this agonist might possibly rely upon additional $\mathrm{Ca}^{2+}$ storing compartments/subcompartments [35].

3.3. Ang-1- and Ang-2-Dependent MAPK Pathways Are Differently Regulated by $I P_{3}$ and $c A D P R$. Ang-1/Ang-2 signaling via Tie-2 receptor is known to control specific essential steps during angiogenesis, a process involving a complex network of intracellular transduction pathways. The interaction of Ang-1 with Tie-2 in the adult vascular system is essential for ECs survival, migration, and vascular repair. It is known that in ECs Ang-1 induces phosphorylation of AKT [36], ERK1/2 [27], and p38 mitogen-activated protein kinase (MAPKs)
[37]. Alitalo's group [38] demonstrated that Ang-1 and Tie-2 form distinct signaling complexes depending on the presence or absence of inter-ECs adhesion linked to the predominant phosphorylation of AKT and weaker activation of ERK in HUVECs monolayer. The intracellular phosphatidylinositol 3-kinase (PI3K)/AKT pathway is a key regulator of several cellular processes and promotes cell survival in response to various stresses such as nutrient deprivation. Among the many signaling pathways that respond to stress, the members of MAPK family are also essential for maintaining cell viability. Several studies demonstrated that Ang-1 promotes cell survival activating the MAPK and PI3K/AKT pathways $[16,19]$. During the early stages of angiogenesis, neovascular sprouts are composed primarily by ECs. As they mature, microvessels acquire a coating of mural cells, which are critical for the development and maintenance of functional vasculature. In a rat aorta model [39] p38 MAPK has been shown to transduce signals critical for vascular remodeling and maturation. With the aim of identifying the involvement of $\mathrm{Ca}^{2+}$ in Angs-dependent signaling events, we evaluated the 

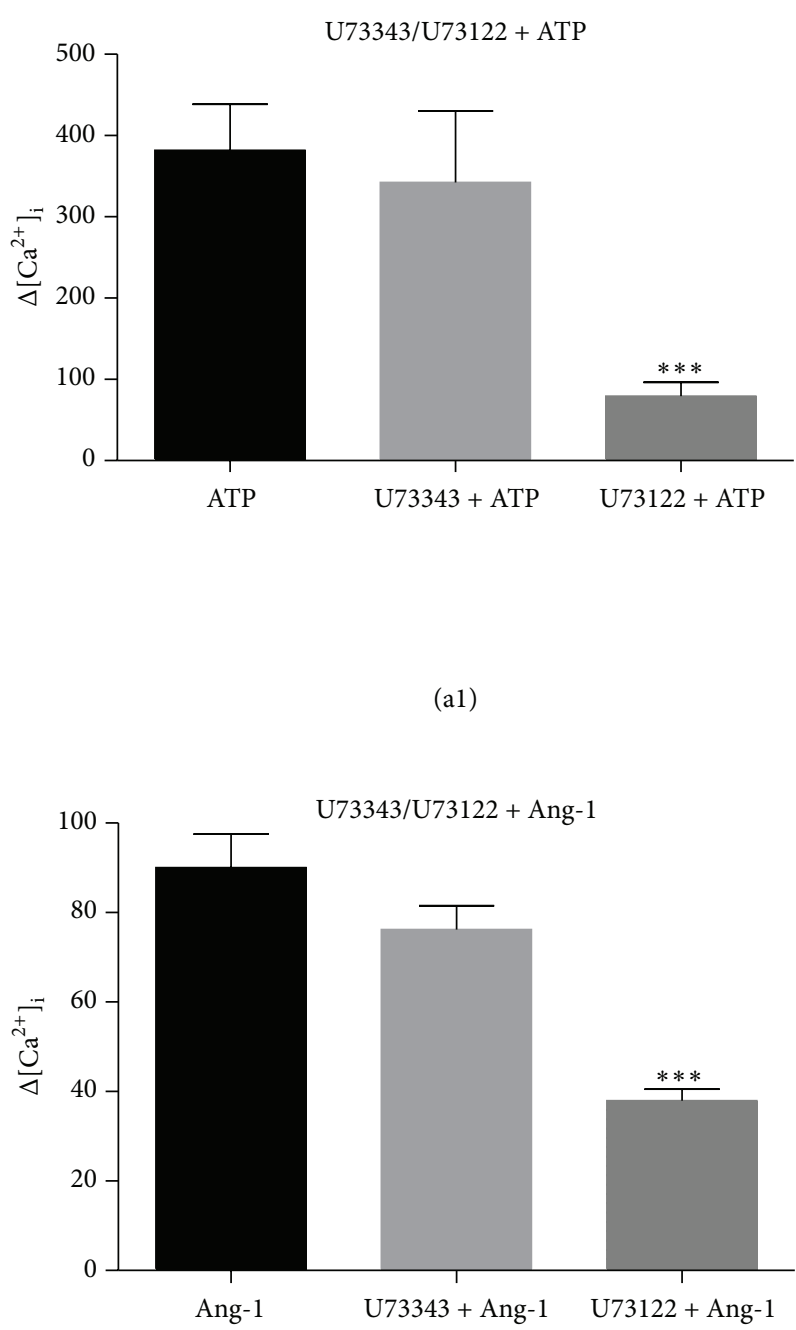

(a3)

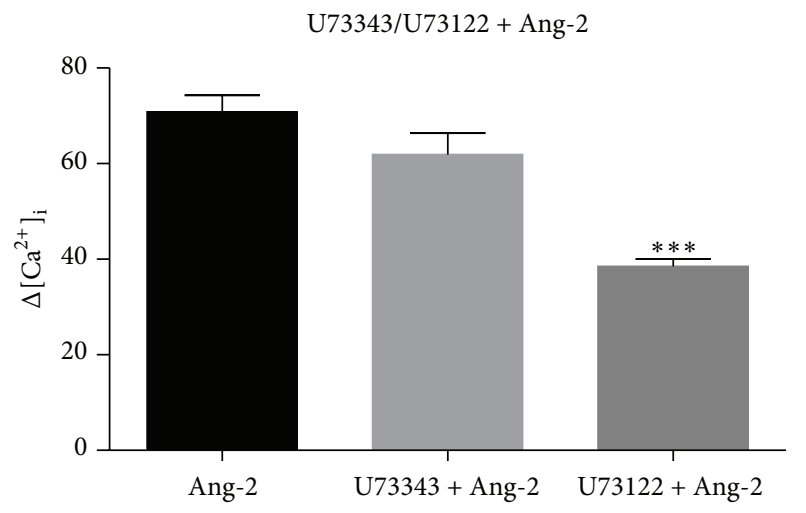

(a5)

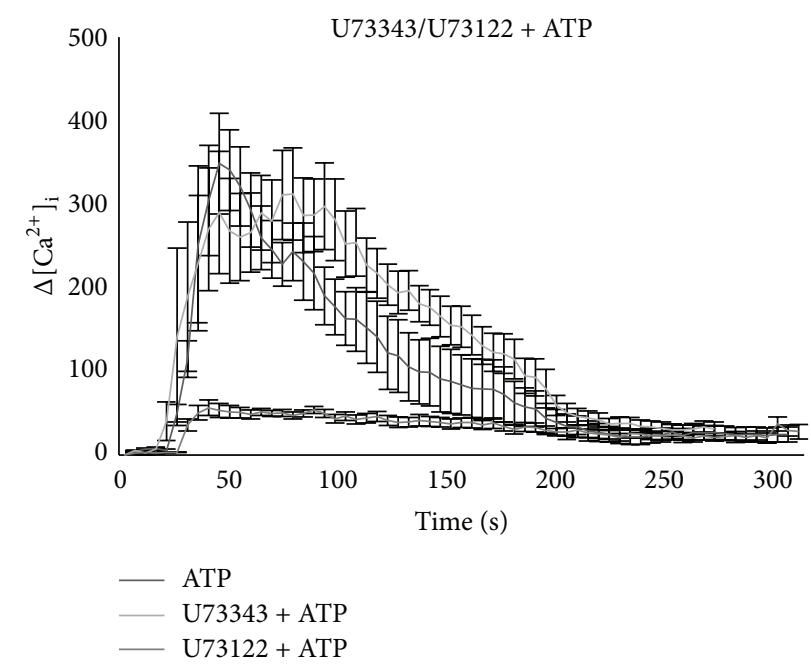

(a2)

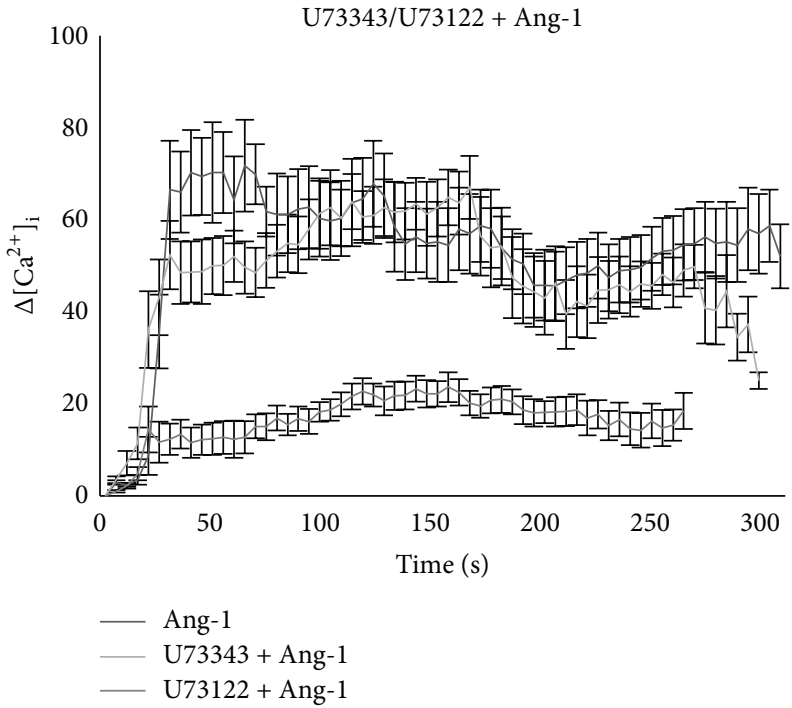

(a4)

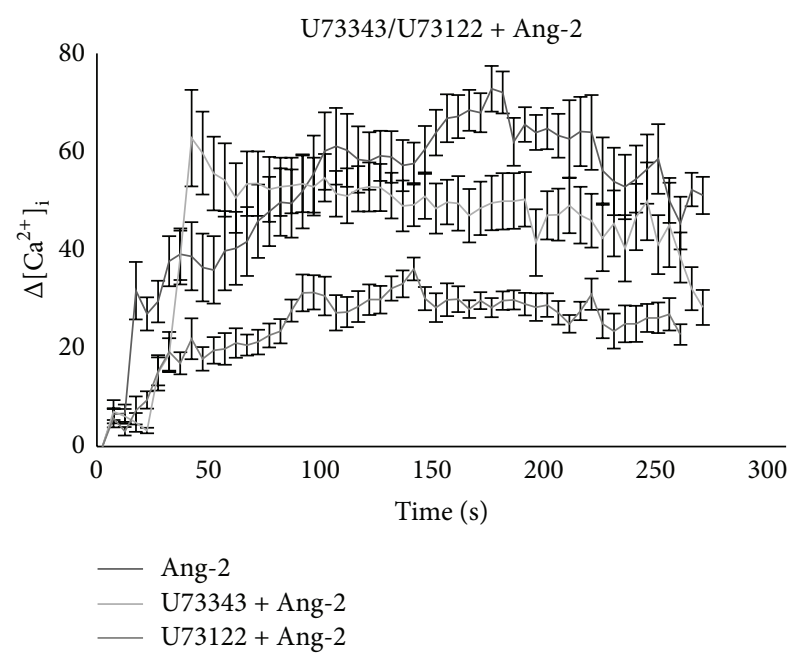

(a6)

(a)

Figure 3: Continued. 

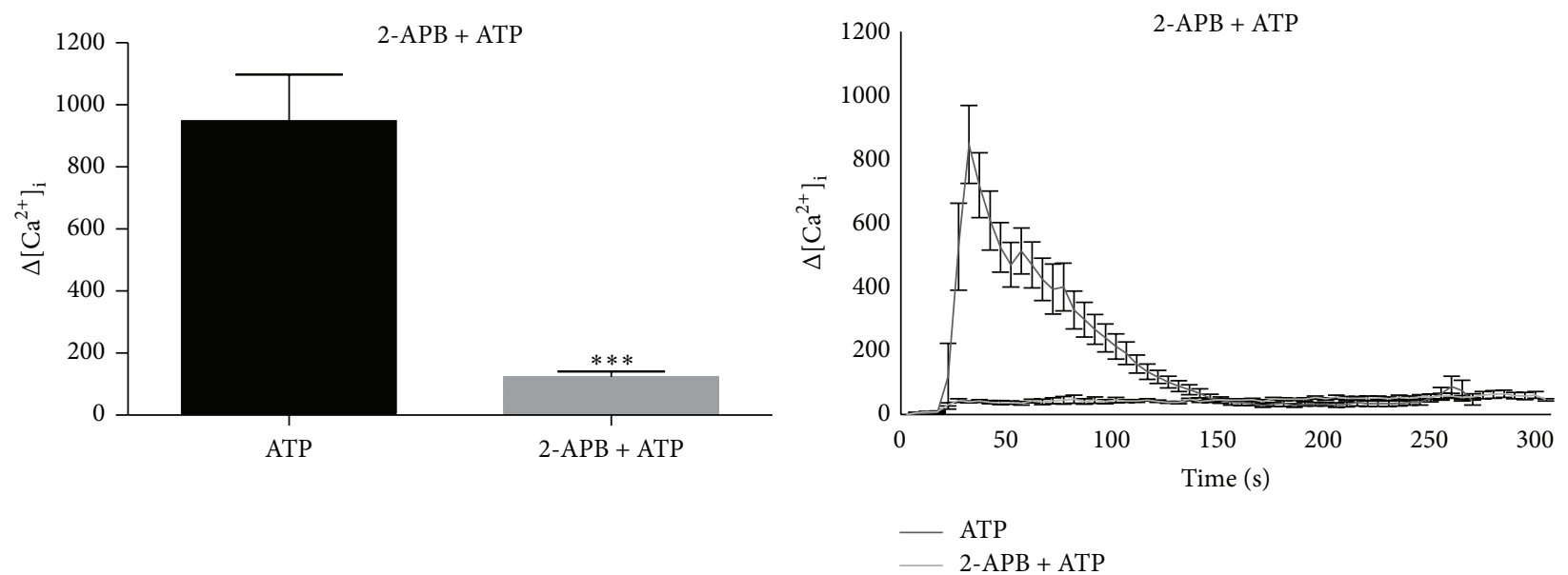

(b1)
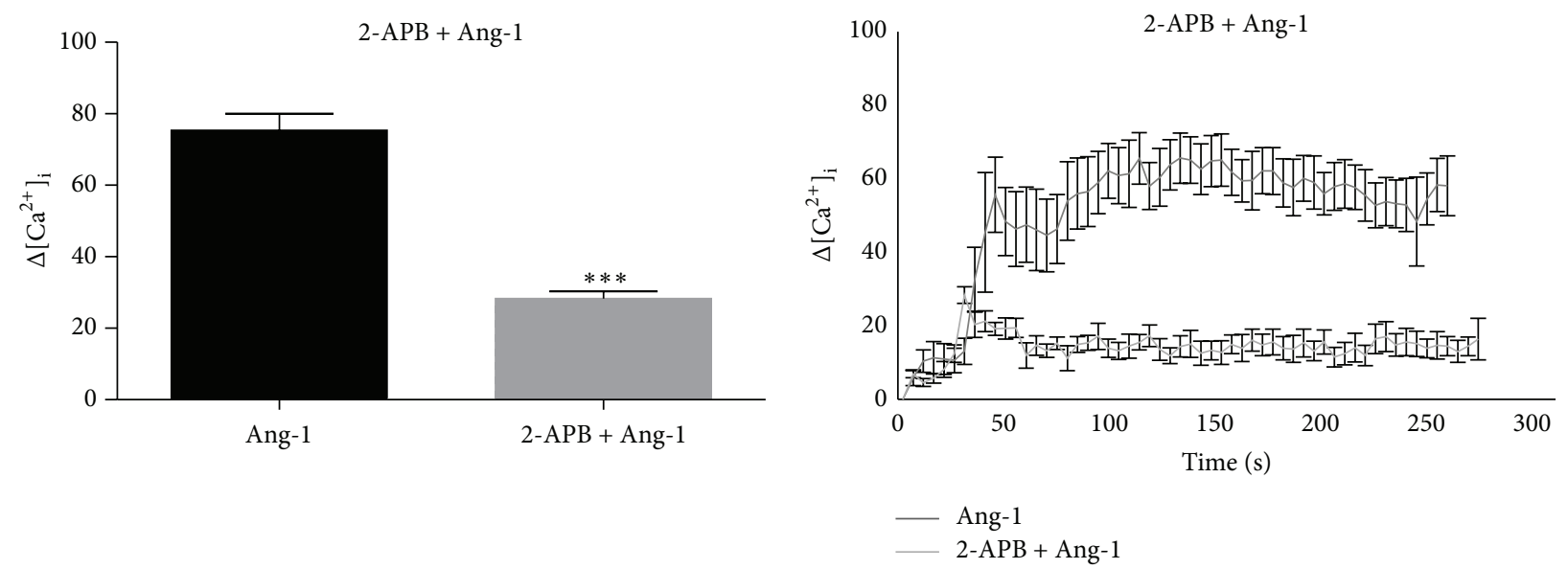

(b3)
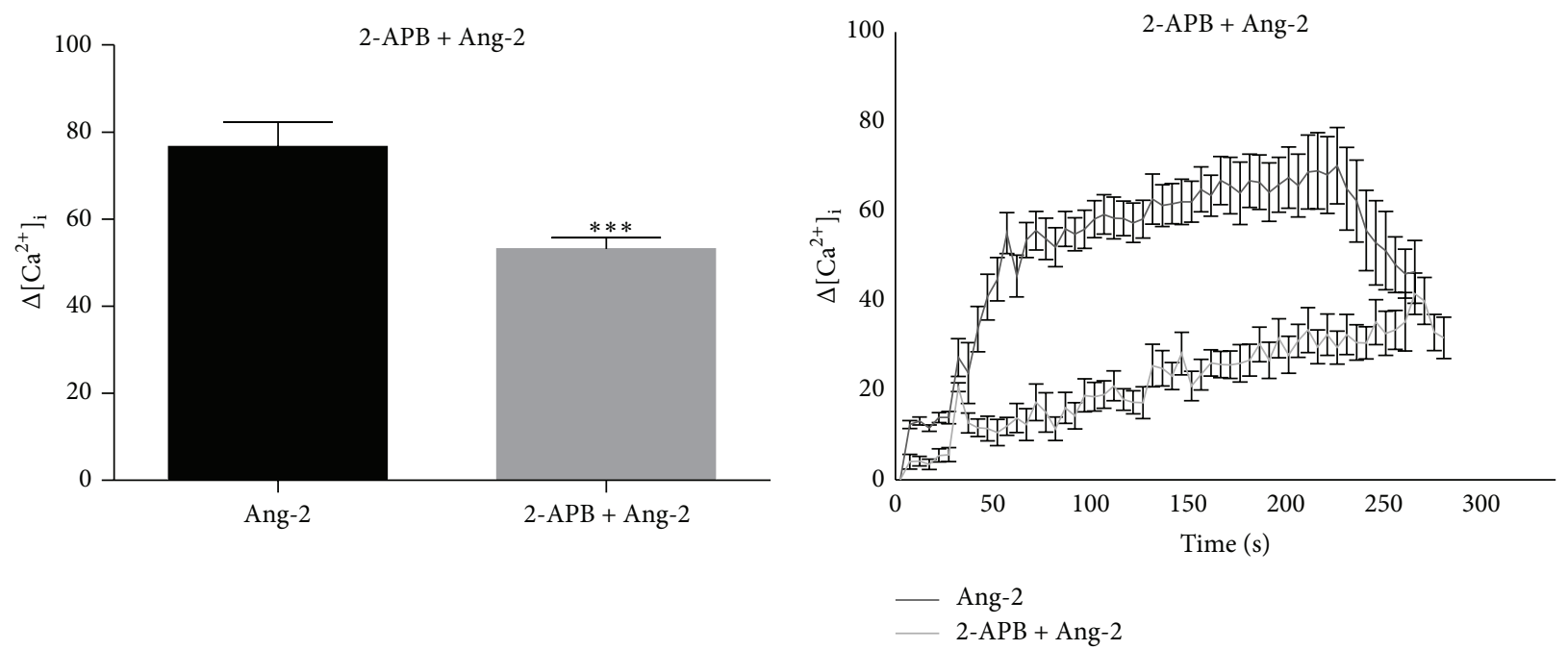

(b5)

(b6)

(b)

FIgURE 3: Ang-1- and Ang-2-dependent $\left[\mathrm{Ca}^{2+}\right]_{\mathrm{i}}$ mobilization is inhibited by antagonists of PLC and of $\mathrm{IP}_{3} \mathrm{R}$. Cells pretreated for 20 min with $2 \mu \mathrm{M}$ U73122 (antagonist of PLC) or U73343 (its nonfunctional analogue) and cells pretreated for 30 min with $75 \mu \mathrm{M} 2$-APB (selective antagonist of $\mathrm{IP}_{3}$ receptor) were stimulated with $10 \mu \mathrm{M}$ ATP (positive control) or Angs in $\mathrm{Ca}^{2+}$-free medium KHH. Statistical evaluation of $\Delta\left[\mathrm{Ca}^{2+}\right]_{\mathrm{i}}$ in response to each agonist in the presence or absence of the indicated inhibitors (a1, a3, a5, b1, b3, and b5). Changes in $\left[\mathrm{Ca}{ }^{2+}\right]_{\mathrm{i}}$ levels are shown as representative traces indicating the effect of U73122/U73343 or 2-APB on cells stimulated with ATP or Ang-1 or Ang-2 in $\mathrm{Ca}^{2+}$-free medium (a2, a4, a6, b2, b4, and b6). $\Delta$ on the $y$-axes $=\mathrm{nM}$. Data in bar charts represent mean \pm s.e.m. from three independent experiments. Cell number $=88-140 .{ }^{* * *} P<0.001$ versus agonists by Student's $t$-test. $\left[\mathrm{Ca}^{2+}\right]_{\mathrm{i}}$ values in representative traces are expressed as increase with respect to basal $\mathrm{Ca}^{2+}$ concentrations $(\Delta)$. 


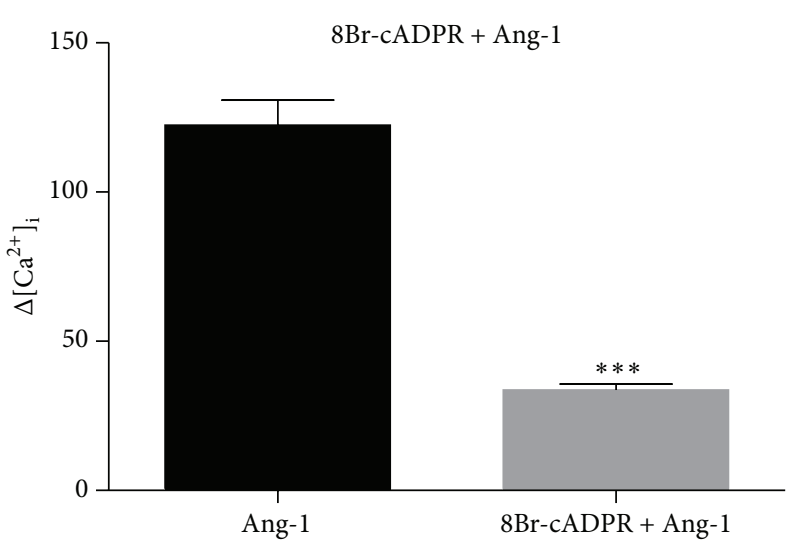

(a1)

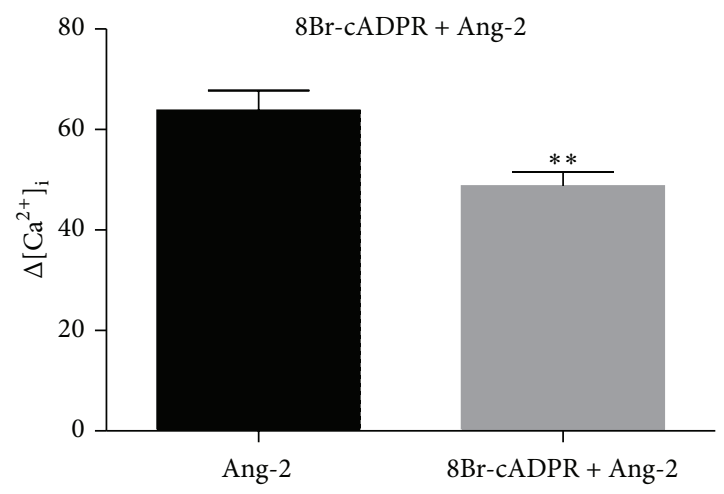

(a3)

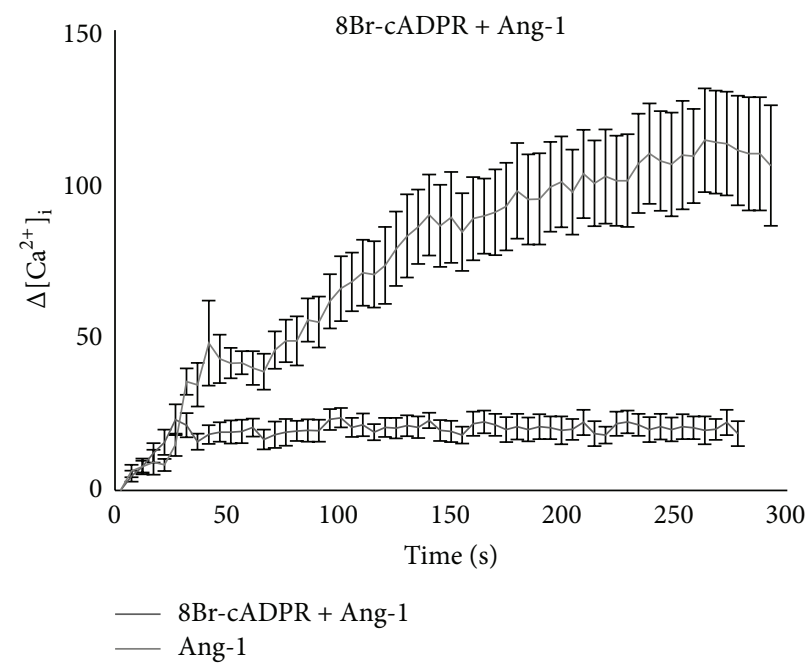

(a2)

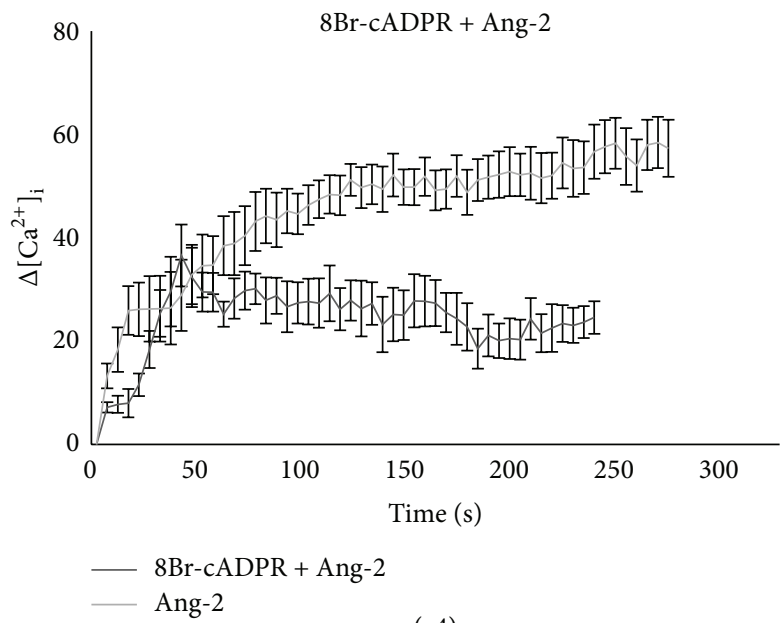

(a4)

FIGURE 4: RyR inhibition abates both Ang-1- and Ang-2-mediated intracellular calcium mobilization. Cells were pretreated for 30 min with $30 \mu \mathrm{M} 8 \mathrm{Br}-\mathrm{cADPR}$ (inactive analogue of cADPR) and then stimulated with Ang-1 or Ang-2 in $\mathrm{Ca}^{2+}$-free medium KHH. Histograms show changes in $\left[\mathrm{Ca}^{2+}\right]_{\mathrm{i}}$ levels in response to each agonist in the presence or absence of the indicated inhibitor (al, a3). Representative traces showing the effect of $8 \mathrm{Br}$-cADPR on Ang-1-stimulated (a2) and Ang-2-stimulated (a4) cells. $\Delta$ on the $y$-axes $=\mathrm{nM}$. Data in bar charts represent mean \pm s.e.m. of three independent experiments. Cell number $=96-132 .{ }^{* *} P<0.01,{ }^{* * *} P<0.001$ versus agonist by Student's $t$-test. $\left[\text { Ca }{ }^{2+}\right]_{\mathrm{i}}$ values in representative traces are expressed as increase with respect to basal $\mathrm{Ca}^{2+}$ concentrations $(\Delta)$.

activation of their known protein targets ERK1/2, AKT, and p38. HUVECs were pretreated or not with the $\mathrm{Ca}^{2+}$ chelator BAPTA-AM at the concentration of $20 \mu \mathrm{M}$. As shown in Figure 5(a) and Figures S1 A-F (in Supplementary Material available online at http://dx.doi.org/10.1155/2015/965271), both Angs activate the phosphorylation of AKT, ERK1/2, and p38 and the combined treatment with BAPTA-AM was found to inhibit both Ang-1- and Ang-2-dependent AKT phosphorylation, while the phosphorylation of ERK1/2 was not affected. The lack of intracellular calcium had an opposite effect on p38 phosphorylation. To further evaluate the specific contribution of the different $\mathrm{Ca}^{2+}$ mobilizing second messengers in AKT phosphorylation, we performed Western blot analysis of cells with two specific inhibitors, either 2-APB (for $\mathrm{IP}_{3} / \mathrm{IP}_{3} \mathrm{R}$ ) or 8Br-cADPR (for cADPR/RyR) prior to Angs stimulation. As shown in Figures 5(b) and 5(c) and Figures S1 G-L, the phosphorylation of AKT is differentially regulated by the two Angs. Pretreatment with 2APB specifically reduced the extent of AKT phosphorylation resulting from stimulation with Ang-1 suggesting the requirement of $\mathrm{IP}_{3}$-dependent $\mathrm{Ca}^{2+}$ release (Figures 5(bl) and 5(c1)), while cADPR/RyR signaling is significantly not involved in this response to either Ang-1 or Ang-2 (Figures 5(b2) and $5(\mathrm{c} 2))$.

3.4. Different $\mathrm{Ca}^{2+}$ Signatures Regulate the Cell Migratory Response to Ang-1 and Ang-2. During neovascularization and angiogenesis ECs degrade the basement membrane and migrate into the perivascular stroma in response to a gradient of angiogenic factors. Cell migration and invasion of extracellular matrix beneath the basement membrane are essential steps involving reorganization of the actin cytoskeleton. The 


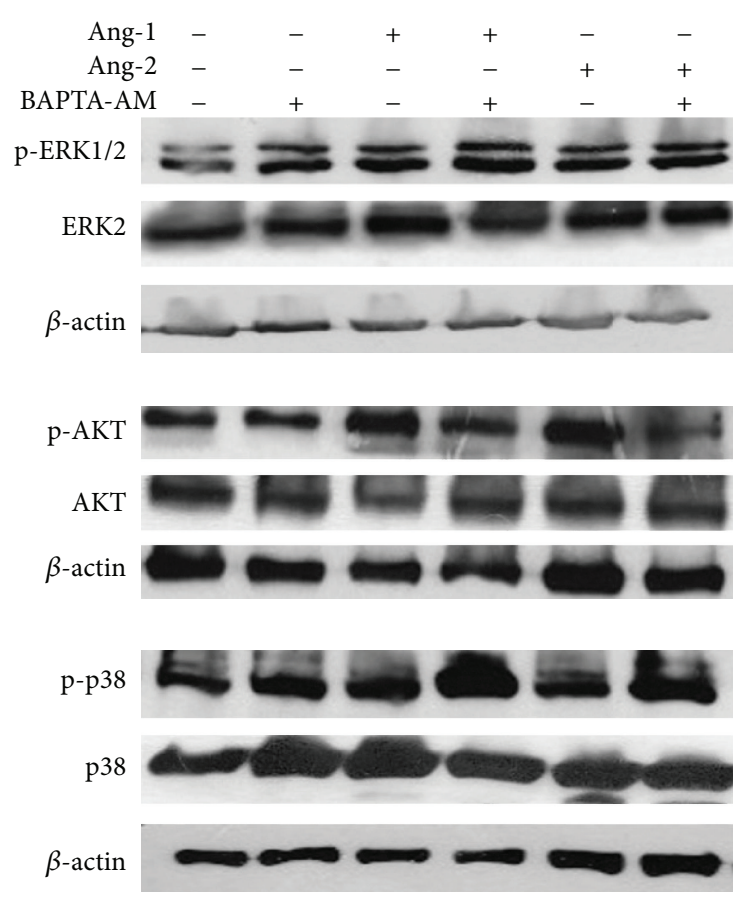

(a)

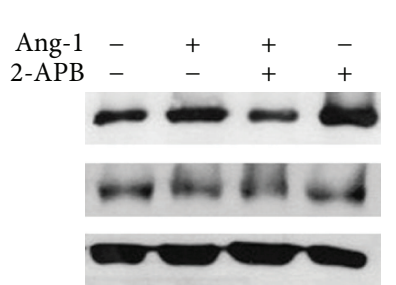

(b1)

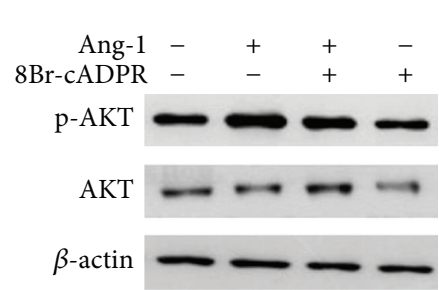

(b2)

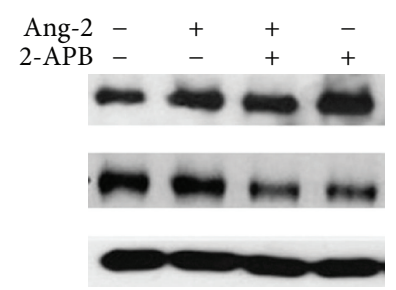

(c1)

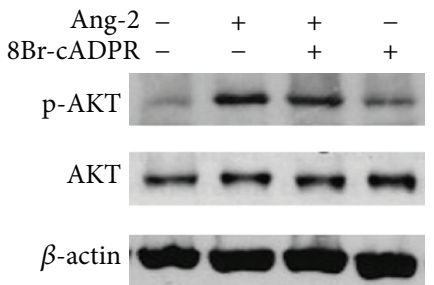

(c1)

(b)

(c)

FIgURE 5: Calcium-dependent AKT and MAPK activation upon Ang-1/Ang-2 stimulation. Ang-1 and Ang-2 induce Ca ${ }^{2+}$-dependent AKT, ERK1/2, and 38 phosphorylation. Confluent HUVECs were pretreated or not with $20 \mu \mathrm{M}$ BAPTA-AM for $1 \mathrm{~h}$ and stimulated with $100 \mathrm{ng} / \mathrm{mL}$ Ang-1 or $200 \mathrm{ng} / \mathrm{mL}$ Ang-2 for $30 \mathrm{~min}$. Blots of total cell lysate were probed for the phosphorylation of downstream targets AKT, ERK1/2, and p38. To ensure equal loading membranes were reprobed for the total amount of the indicated proteins and for $\beta$-actin. Representative blots are shown from three to five independent experiments (a). Cells pretreated or not with $75 \mu \mathrm{M} 2-\mathrm{APB}$ or $30 \mu \mathrm{M} 8 \mathrm{Br}-\mathrm{cADPR}$ and stimulated with either Ang-1 or Ang-2. Blots of total cell lysate were probed for the phosphorylation of downstream target AKT. To ensure equal loading membranes were reprobed for the total amount of the indicated protein and for $\beta$-actin. Representative blots are shown from three independent experiments (b1, b2, c1, and c2).

focal adhesion kinase FAK, a member of nonreceptor tyrosine kinases, plays a key role in regulating the dynamic changes in actin cytoskeleton reorganization involved in migration and adhesion. Ang-1 induces capillary sprouting activity through nondirectional and directional migration mediated by Tie- 2 but not Tie-1 receptor and induces tyrosine phosphorylation of FAK which is dependent on PI3K activity [40-43]. To identify the possible involvement of $\left[\mathrm{Ca}^{2+}\right]_{\mathrm{i}}$ rise in Angsdependent activation of $\mathrm{p}$-FAK, we performed Western blot analysis in cells treated or not with the $\mathrm{Ca}^{2+}$ chelator BAPTA$\mathrm{AM}$ at the concentration of $20 \mu \mathrm{M}$ prior to stimulation with either Ang-1 or Ang-2. We observed that both Angs activate p-FAK through a $\mathrm{Ca}^{2+}$-dependent mechanism (Figure 6(a), Figures S2 A-B). To evaluate the contribution of the different second messengers involved, cells were pretreated with two specific inhibitors, 2-APB and 8Br-cADPR. FAK phosphorylation induced by Angs was found to depend on $\mathrm{IP}_{3}$ signal in cells stimulated with Ang-1 (Figures 6(b1) and 6(b2)) and strongly by both second messengers in those stimulated with Ang-2 (Figures 6(c1) and 6(c2), Figures S2 C-F). To further test the specific involvement of $\mathrm{IP}_{3}$ and cADPR in Ang-1- and Ang-2-induced cell motility, we performed a "scratch assay" in which confluent ECs monolayer is manually wounded along a narrow line and subsequent cell migration to reform the monolayer can be studied. The advantage of this method is that cell migration can be monitored over time, thus allowing us to estimate the rate of migratory response. Quantification is arbitrary, depending on size of wound and 


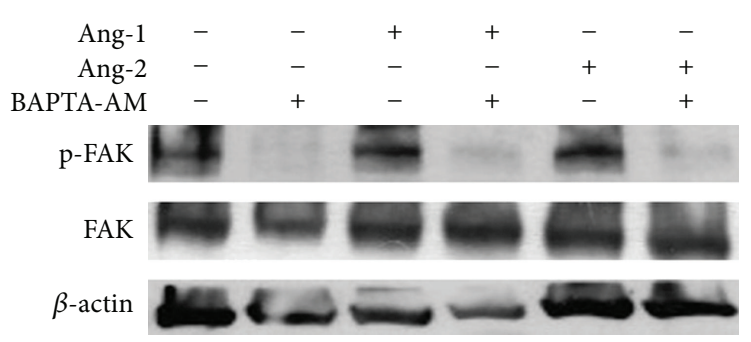

(a)

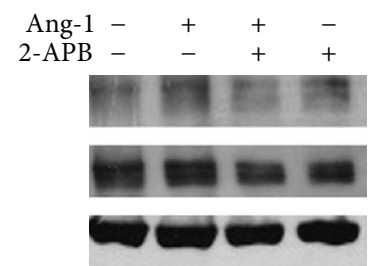

(b1)

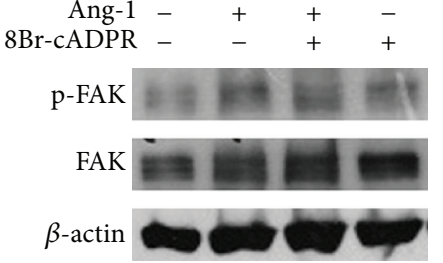

(b2)

(b)

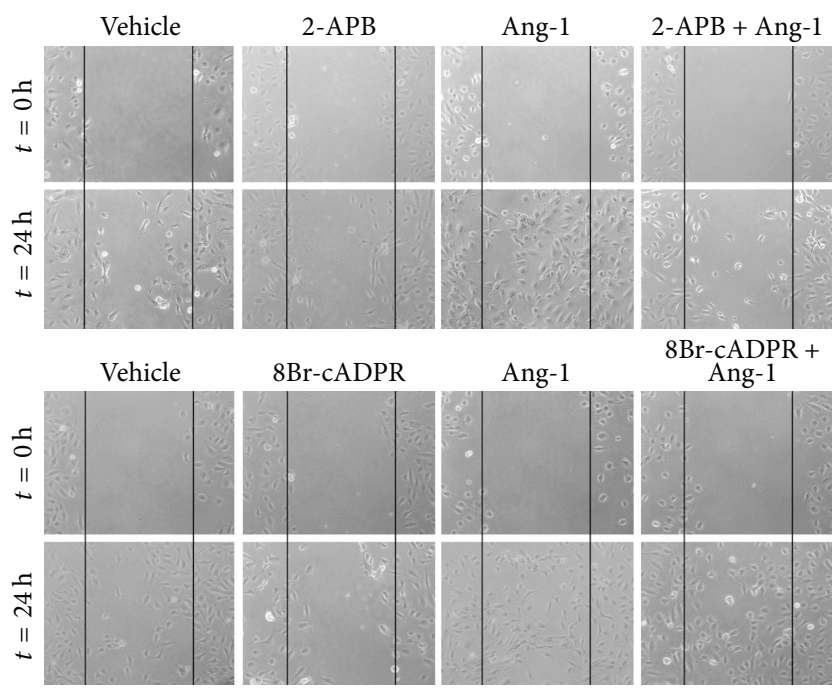

(d)

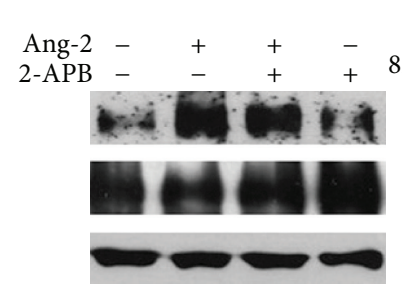

(c1)

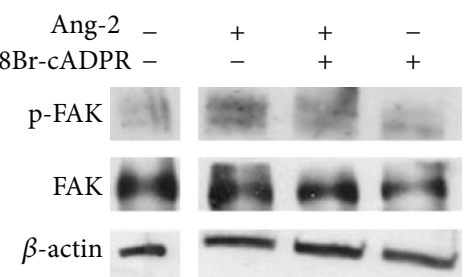

(c1)

(c)

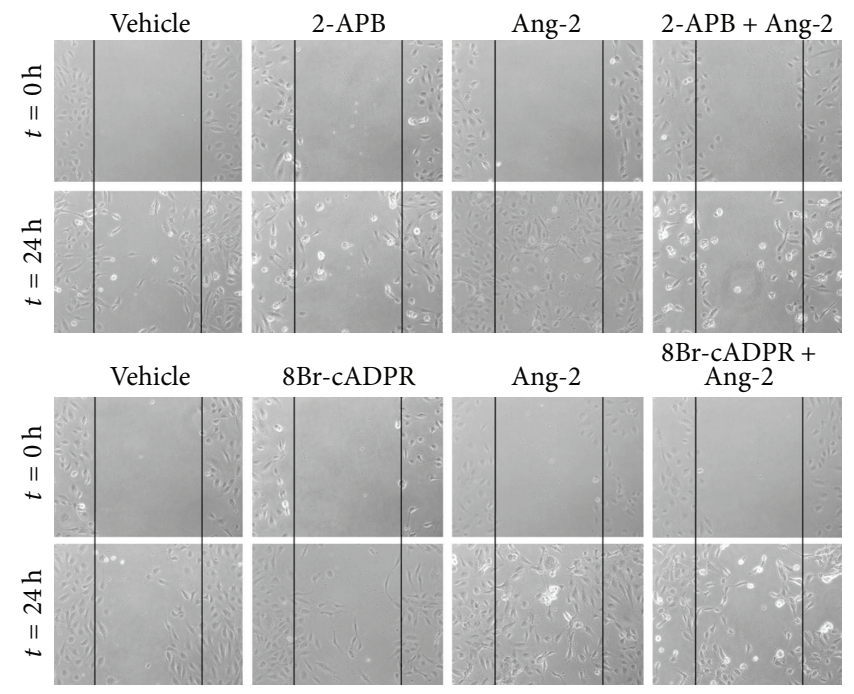

(e)

FIgURE 6: 2-APB and 8Br-cADPR impair Angs-dependent cell migration on HUVECs. Ang-1 and Ang-2 induce Ca ${ }^{2+}$-dependent FAK phosphorylation. Confluent HUVECs were pretreated or not with $20 \mu \mathrm{M}$ BAPTA-AM for $1 \mathrm{~h}$ and stimulated with $100 \mathrm{ng} / \mathrm{mL}$ Ang-1 or $200 \mathrm{ng} / \mathrm{mL}$ Ang-2 for $30 \mathrm{~min}$. Blots of total cell lysate were probed for the phosphorylation of downstream target FAK. To ensure equal loading membranes were reprobed for the total amount of the indicated protein and for $\beta$-actin (a). Cells pretreated or not with $75 \mu \mathrm{M} 2$ $\mathrm{APB}$ or $30 \mu \mathrm{M} 8 \mathrm{Br}-\mathrm{cADPR}$ and stimulated with either Ang-1 or Ang-2 (b1, b2, c1, and c2). Representative blots are shown from three to five independent experiments. Ang-1-induced EC migration is affected by treatment with the second messengers inhibitor 2-APB while Ang-2induced cell migration appears to be both $\mathrm{IP}_{3}$ - and $\mathrm{cADPR}$-dependent. Scratch assay to evaluate the cell migration capability in the indicated experimental conditions. Wounded monolayers at the time of manual damage ( $t=0 \mathrm{~h}$ upper panel) and after $24 \mathrm{~h}$ treatment (lower panel) with Ang-1 (d), Ang-2 (e), and inhibitors as indicated. Pictures are representative of three independent experiments.

cell growth. In order to discriminate between migration and proliferation, flow cytometric assessment of cell proliferation with propidium iodide (PI) was performed (Figure S3). This assay showed that, in the culture conditions of the wound healing assay, ECs do not proliferate under Angs stimulation. From a qualitative point of view, the wound healing assay clearly demonstrated that the capability of ECs to move in $24 \mathrm{~h}$ under Ang-1 stimulation is modified by the treatment with 2-APB, while under Ang-2 stimulation cell migration is reduced by the treatment with either $8 \mathrm{Br}-\mathrm{cADPR}$ or $2-\mathrm{APB}$ (Figures 6(d) and 6(e)).

3.5. Capillary-Like Network Formation Controlled by Ang-1 Is $I P_{3}$-Dependent. The formation of capillary-like structures in vivo is considered as representative of later, differentiative stages of angiogenesis and is commonly assayed to test the efficiency of compounds with pro- or antiangiogenic functions. The Angs-Tie axis is essential for vasculogenesis, 


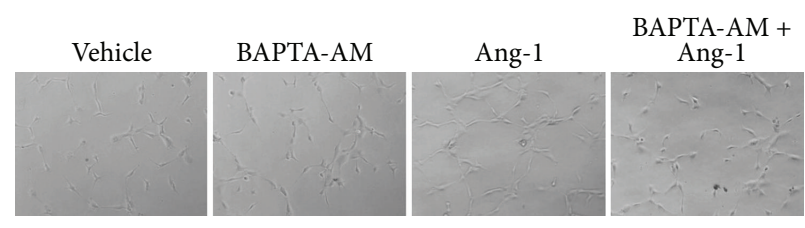

(a)

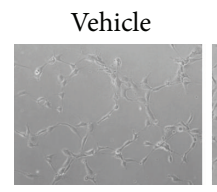

2-APB

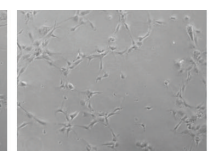

Vehicle

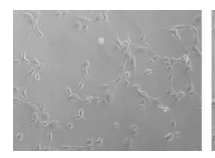

8Br-cADPR

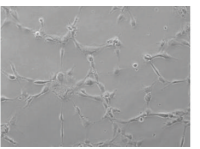

(b)

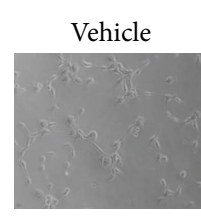

BAPTA-AM
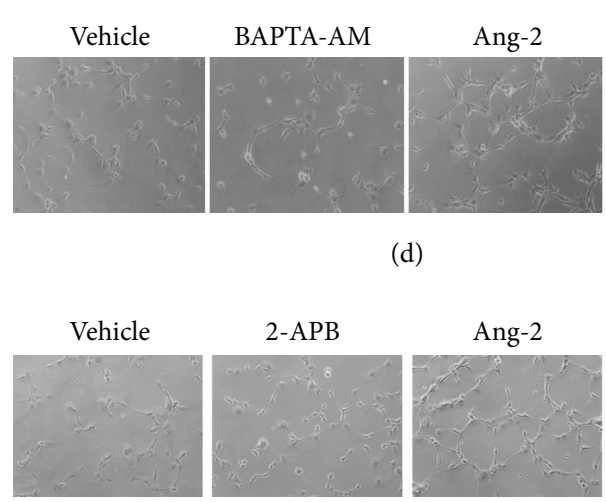

$2-\mathrm{APB}$

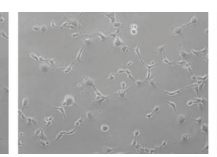

Vehicle

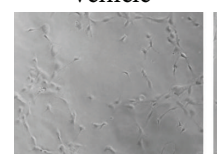

(d)

Ang-1

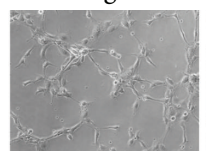

Ang-1
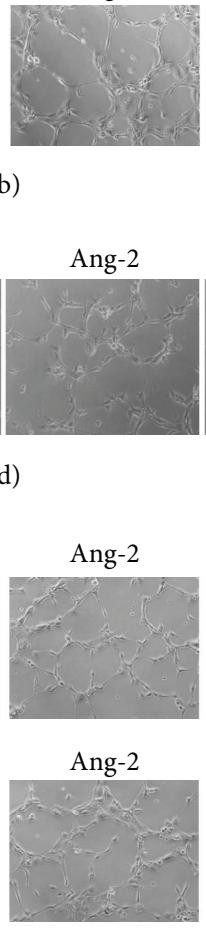

(e)
$2-\mathrm{APB}+$ Ang-1

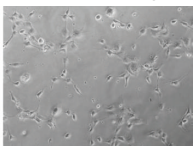

$8 \mathrm{Br}-\mathrm{cADPR}+$ Ang-1

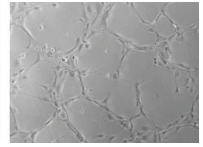

BAPTA-AM + Ang-2

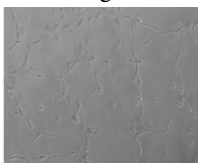

$2-\mathrm{APB}+$ Ang-2

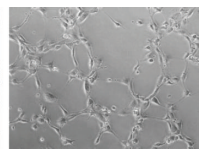

$8 \mathrm{Br}-\mathrm{cADPR}+$ Ang-2

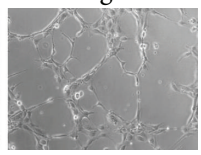

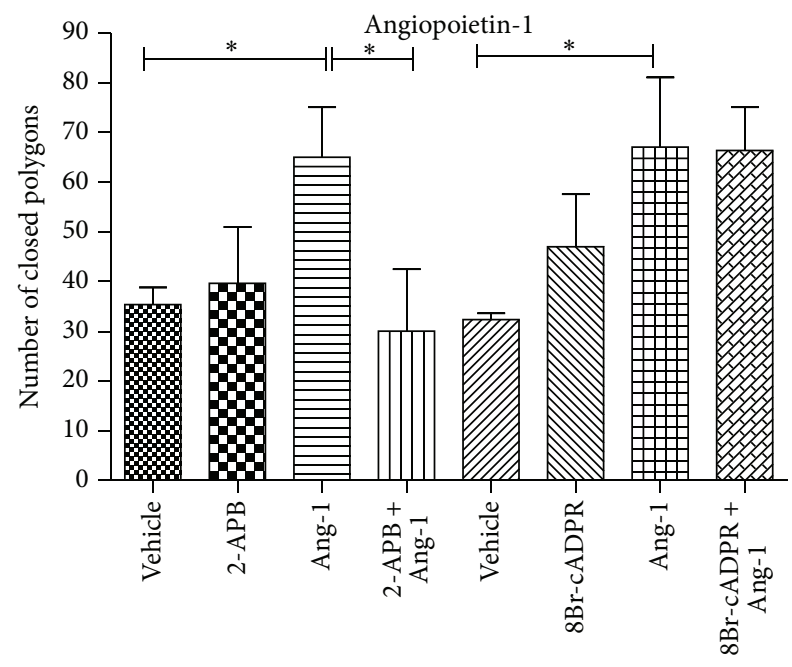

(c)

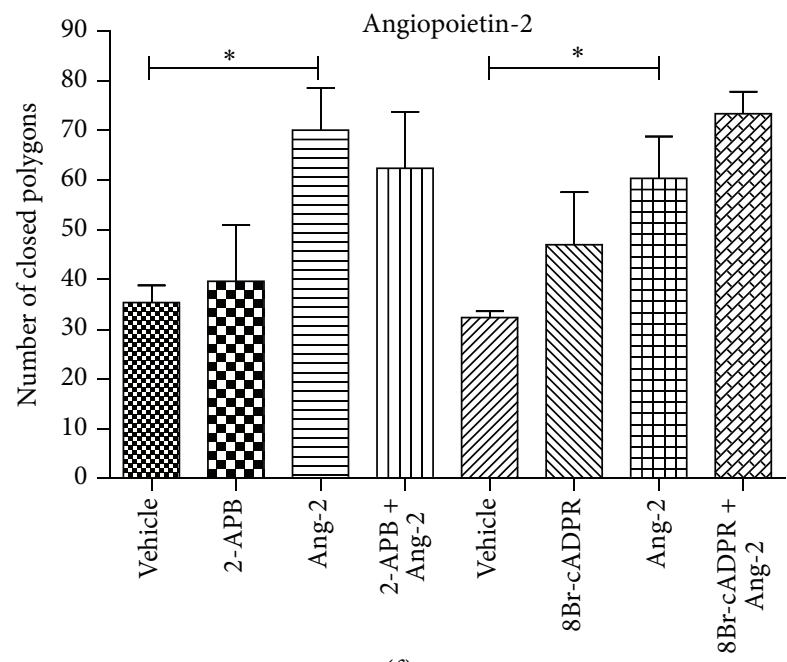

(f)

Figure 7: IP 3 pathway inhibition impairs Ang-1-induced capillary-like formation in vitro. Cells were plated in Matrigel-coated dishes and incubated in EBM-2 + 2\% FBS for $5 \mathrm{~h}$ in the presence or absence of Angs or/and inhibitors as indicated. Each condition was tested in triplicate. Representative images of one of three independent experiments (Ang-1: a, b; Ang-2: d, e). Quantitative evaluation of tube formation as the number of closed polygons formed in seven fields for each experimental condition (c, f). Data in bar charts represent mean \pm s.e.m. of three independent experiments. ${ }^{*} P<0.05$ by Student's $t$-test.

normal vascular development, and angiogenesis. When ECs are plated onto a layer of gel matrix, they are stimulated to migrate and differentiate into tubular-like structures simulating the in vivo process [44]. Matrigel, a complex compound that mimics the extracellular matrix, containing extracellular and basement membrane proteins, is known to be the most potent matrix for tubule formation. This is usually assayed in the presence of potential modulators of angiogenesis and tubule development is observed over a 4 to $24 \mathrm{~h}$ period. Cordlike capillary structures are visualized as close polygons and the degree of complexity of the structure can be quantitatively evaluated counting the number of close polygons or associating a score depending on the number of ECs composing each of them. As shown in Figures 7(a) and 7(d), when plated on Matrigel matrices at high densities, HUVECs form cord-like capillary structures within a few hours, and this process is enhanced by Ang-1 and Ang-2. To evaluate the possible involvement of calcium signals in the regulation of this angiogenic process, cells were pretreated with the $\mathrm{Ca}^{2+}$ chelator BAPTA-AM at the concentration of $20 \mu \mathrm{M}$. The formation of Angs-induced capillary-like structures was impaired by this inhibitor in Ang-1 stimulated samples but unaffected in cells stimulated with Ang-2, indicating that this response to Ang-2 is $\left[\mathrm{Ca}^{2+}\right]_{i}$-independent. To further assess whether $\mathrm{Ca}^{2+}$ signal is dispensable for Ang-2 to induce capillary-like formation, we performed the Matrigel assay in 
the presence of second messengers inhibitors as shown in Figures 7(e) and 7(f) and found no evident inhibition of tube formation. Moreover, to identify by which second messenger Ang-1 controls the formation of capillary-like structures, cells were pretreated with the same second messenger inhibitors. Representative images show that this response to Ang1 was inhibited by 2 -APB pretreatment (Figure 7(b)). An approximate estimate of the efficiency of this process can be inferred by the extent of cellular network formation, whereby cells first align to form linear segments and subsequently interconnect to form closed polygonal structures. As shown in Figure 7(c), the number of closed polygons formed in cells stimulated with Ang-1 in the presence of 2-APB is significantly reduced compared with samples stimulated with Ang-1 alone, indicating the involvement of $\mathrm{IP}_{3}$-mediated $\mathrm{Ca}^{2+}$ signaling in capillary-like formation in vitro.

\section{Conclusions}

During the complex process of angiogenesis, a variety of growth factors and cytokines are upregulated and exert their functions through autocrine/paracrine signaling. Among these, Ang-1 and Ang-2 play important roles. Ang-1 does not stimulate ECs growth but rather promotes stabilization of vascular network and branching morphogenesis in in vitro and in vivo angiogenesis; conversely, Ang-2, a somehow context-dependent antagonist of Ang-1, promotes vessels destabilization favouring pericytes detachment [45]. In the present study, we identified a novel $\mathrm{Ca}^{2+}$-dependent machinery activated by Angs which controls angiogenic processes, including migration and the ability to induce capillary-like structures in vitro. Our data suggest that $\mathrm{Ca}^{2+}$ signaling might be envisaged as a possible "signaling hub" for Angs and other angiogenic factors. Given the therapeutic potential of angiogenesis-blocking therapies based on the inhibition of specific signaling pathways, this concept could open the way to novel experimental approaches in this field.

\section{Conflict of Interests}

The authors declare no conflict of interests.

\section{Authors' Contribution}

Irene Pafumi and Antonio Filippini designed research; Irene Pafumi and Annarita Favia performed research; Irene Pafumi, Annarita Favia, Guido Gambara, Francesca Papacci, Elio Ziparo, and Antonio Filippini analyzed data; Irene Pafumi, Annarita Favia, Fioretta Palombi, and Antonio Filippini wrote the paper.

\section{Acknowledgments}

This work was supported by grants from Ministero dell'Istruzione, dell'Università e della Ricerca (MIUR) and Agenzia Spaziale Italiana (to Antonio Filippini) and from Fondazione Roma (to Elio Ziparo).

\section{References}

[1] S. Fukuhara, K. Sako, K. Noda, K. Nagao, K. Miura, and N. Mochizuki, "Tie2 is tied at the cell-cell contacts and to extracellular matrix by Angiopoietin-1," Experimental \& Molecular Medicine, vol. 41, no. 3, pp. 133-139, 2009.

[2] S. Davis, T. H. Aldrich, P. F. Jones et al., "Isolation of angiopoietin-1, a ligand for the TIE2 receptor, by secretion-trap expression cloning," Cell, vol. 87, no. 7, pp. 1161-1169, 1996.

[3] H. Huang, A. Bhat, G. Woodnutt, and R. Lappe, "Targeting the ANGPT-TIE2 pathway in malignancy," Nature Reviews Cancer, vol. 10, no. 8, pp. 575-585, 2010.

[4] L. Eklund and P. Saharinen, "Angiopoietin signaling in the vasculature," Experimental Cell Research, vol. 319, no. 9, pp. 12711280, 2013.

[5] K. J. Kim, B. Li, J. Winer et al., "Inhibition of vascular endothelial growth factor-induced angiogenesis suppresses tumour growth in vivo," Nature, vol. 362, no. 6423, pp. 841-844, 1993.

[6] H. Hurwitz, L. Fehrenbacher, W. Novotny et al., "Bevacizumab plus irinotecan, fluorouracil, and leucovorin for metastatic colorectal cancer," The New England Journal of Medicine, vol. 350, no. 23, pp. 2335-2342, 2004.

[7] N. M. Biel and D. W. Siemann, "Targeting the Angiopoietin2/Tie-2 axis in conjunction with VEGF signal interference," Cancer Letters, 2014.

[8] P. Carmeliet and R. K. Jain, "Principles and mechanisms of vessel normalization for cancer and other angiogenic diseases," Nature Reviews Drug Discovery, vol. 10, no. 6, pp. 417-427, 2011.

[9] G. Bergers and D. Hanahan, "Modes of resistance to antiangiogenic therapy," Nature Reviews Cancer, vol. 8, no. 8, pp. 592-603, 2008.

[10] H. G. Augustin, G. Y. Koh, G. Thurston, and K. Alitalo, "Control of vascular morphogenesis and homeostasis through the angiopoietin-Tie system," Nature Reviews Molecular Cell Biology, vol. 10, no. 3, pp. 165-177, 2009.

[11] M. Thomas and H. G. Augustin, "The role of the angiopoietins in vascular morphogenesis," Angiogenesis, vol. 12, no. 2, pp. 125$137,2009$.

[12] P. C. Maisonpierre, C. Suri, P. F. Jones et al., "Angiopoietin-2, a natural antagonist for Tie2 that disrupts in vivo angiogenesis," Science, vol. 277, no. 5322, pp. 55-60, 1997.

[13] N. W. Gale, G. Thurston, S. F. Hackett et al., "Angiopoietin-2 is required for postnatal angiogenesis and lymphatic patterning, and only the latter role is rescued by angiopoietin-1," Developmental Cell, vol. 3, no. 3, pp. 411-423, 2002.

[14] T. C. M. Seegar, B. Eller, D. Tzvetkova-Robev et al., "Tie1-Tie2 interactions mediate functional differences between angiopoietin ligands," Molecular Cell, vol. 37, no. 5, pp. 643-655, 2010.

[15] G. Thurston and C. Daly, "The complex role of angiopoietin-2 in the angiopoietin-Tie signaling pathway," Cold Spring Harbor Perspectives in Medicine, 2012.

[16] I. Kim, J.-H. Kim, S.-O. Moon, H. J. Kwak, N.-G. Kim, and G. Y. Koh, "Angiopoietin-2 at high concentration can enhance endothelial cell survival through the phosphatidylinositol 3/kinase/Akt signal transduction pathway," Oncogene, vol. 19, no. 39, pp. 4549-4552, 2000.

[17] K. Teichert-Kuliszewska, P. C. Maisonpierre, N. Jones et al., "Biological action of angiopoietin-2 in a fibrin matrix model of angiogenesis is associated with activation of Tie2," Cardiovascular Research, vol. 49, no. 3, pp. 659-670, 2001. 
[18] C. Daly, E. Pasnikowski, E. Burova et al., "Angiopoietin-2 functions as an autocrine protective factor in stressed endothelial cells," Proceedings of the National Academy of Sciences of the United States of America, vol. 103, no. 42, pp. 15491-15496, 2006.

[19] K. Fujikawa, I. de Aos Scherpenseel, S. K. Jain, E. Presman, R. A. Christensen, and L. Varticovski, "Role of PI 3-kinase in angiopoietin-1-mediated migration and attachment-dependent survival of endothelial cells," Experimental Cell Research, vol. 253, no. 2, pp. 663-672, 1999.

[20] I. Kim, H. G. Kim, J.-N. So, J. H. Kim, H. J. Kwak, and G. Y. Koh, "Angiopoietin-1 regulates endothelial cell survival through the phosphatidylinositol 3/-kinase/Akt signal transduction pathway," Circulation Research, vol. 86, no. 1, pp. 24-29, 2000.

[21] D. P. Hughes, M. B. Marron, and N. P. J. Brindle, "The antiinflammatory endothelial tyrosine kinase Tie2 interacts with a novel nuclear factor- $\kappa$ B inhibitor ABIN-2," Circulation Research, vol. 92, no. 6, pp. 630-636, 2003.

[22] U. Fiedler, M. Scharpfenecker, S. Koidl et al., "The Tie-2 ligand Angiopoietin-2 is stored in and rapidly released upon stimulation from endothelial cell Weibel-Palade bodies," Blood, vol. 103, no. 11, pp. 4150-4156, 2004.

[23] Y.-Q. Huang, J.-J. Li, L. Hu, M. Lee, and S. Karpatkin, “Thrombin induces increased expression and secretion of angiopoietin2 from human umbilical vein endothelial cells," Blood, vol. 99, no. 5, pp. 1646-1650, 2002.

[24] I. Helfrich, L. Edler, A. Sucker et al., "Angiopoietin-2 levels are associated with disease progression in metastatic malignant melanoma," Clinical Cancer Research, vol. 15, no. 4, pp. 13841392, 2009.

[25] K. M. Detjen, S. Rieke, A. Deters et al., "Angiopoietin-2 promotes disease progression of neuroendocrine tumors," Clinical Cancer Research, vol. 16, no. 2, pp. 420-429, 2010.

[26] V. Goede, O. Coutelle, J. Neuneier et al., "Identification of serum angiopoietin-2 as a biomarker for clinical outcome of colorectal cancer patients treated with bevacizumab-containing therapy," British Journal of Cancer, vol. 103, no. 9, pp. 1407-1414, 2010.

[27] S. Fukuhara, K. Sako, T. Minami et al., "Differential function of Tie 2 at cell-cell contacts and cell-substratum contacts regulated by angiopoietin-1," Nature Cell Biology, vol. 10, no. 5, pp. 513$526,2008$.

[28] M. J. Berridge, M. D. Bootman, and H. L. Roderick, "Calcium signalling: dynamics, homeostasis and remodelling," Nature Reviews Molecular Cell Biology, vol. 4, no. 7, pp. 517-529, 2003.

[29] A. Galione and G. C. Churchill, "Interactions between calcium release pathways: multiple messengers and multiple stores," Cell Calcium, vol. 32, no. 5-6, pp. 343-354, 2002.

[30] A. J. Morgan, F. M. Platt, E. Lloyd-Evans, and A. Galione, "Molecular mechanisms of endolysosomal $\mathrm{Ca}^{2+}$ signalling in health and disease," Biochemical Journal, vol. 439, no. 3, pp. 349374, 2011.

[31] B. Esposito, G. Gambara, A. M. Lewis et al., "NAADP links histamine $\mathrm{H} 1$ receptors to secretion of von Willebrand factor in human endothelial cells," Blood, vol. 117, no. 18, pp. 4968-4977, 2011.

[32] A. Favia, M. Desideri, G. Gambara et al., "VEGF-induced neoangiogenesis is mediated by NAADP and two-pore channel2-dependent $\mathrm{Ca}^{2+}$ signaling," Proceedings of the National Academy of Sciences of the United States of America, vol. 111, no. 44, pp. E4706-E4715, 2014.
[33] G. Grynkiewicz, M. Poenie, and R. Y. Tsien, "A new generation of $\mathrm{Ca}^{2+}$ indicators with greatly improved fluorescence properties," The Journal of Biological Chemistry, vol. 260, no. 6, pp. 3440-3450, 1985.

[34] M. J. Berridge, "Inositol trisphosphate and calcium signalling mechanisms," Biochimica et Biophysica Acta-Molecular Cell Research, vol. 1793, no. 6, pp. 933-940, 2009.

[35] M. Brini and E. Carafoli, "Calcium pumps in health and disease," Physiological Reviews, vol. 89, no. 4, pp. 1341-1378, 2009.

[36] A. Papapetropoulos, D. Fulton, K. Mahboubi et al., "Angiopoietin-1 inhibits endothelial cell apoptosis via the Akt/survivin pathway," The Journal of Biological Chemistry, vol. 275, no. 13, pp. 9102-9105, 2000.

[37] W.-H. Zhu, J. Han, and R. F. Nicosia, "Requisite role of p38 MAPK in mural cell recruitment during angiogenesis in the rat aorta model," Journal of Vascular Research, vol. 40, no. 2, pp. 140-148, 2003.

[38] P. Saharinen, L. Eklund, J. Miettinen et al., "Angiopoietins assemble distinct Tie2 signalling complexes in endothelial cellcell and cell-matrix contacts," Nature Cell Biology, vol. 10, no. 5, pp. 527-537, 2008.

[39] W. H. Zhu, A. MacIntyre, and R. F. Nicosia, "Regulation of angiogenesis by vascular endothelial growth factor and angiopoietin-1 in the rat aorta model: distinct temporal patterns of intracellular signaling correlate with induction of angiogenic sprouting," The American Journal of Pathology, vol. 161, no. 3, pp. 823-830, 2002.

[40] I. Kim, H. G. Kim, S. O. Moon et al., "Angiopoietin-1 induces endothelial cell sprouting through the activation of focal adhesion kinase and plasmin secretion," Circulation Research, vol. 86, no. 9, pp. 952-959, 2000.

[41] M. Felcht, R. Luck, A. Schering et al., "Angiopoietin-2 differentially regulates angiogenesis through TIE2 and integrin signaling," The Journal of Clinical Investigation, vol. 122, no. 6, pp. 1991-2005, 2012.

[42] I. Cascone, E. Audero, E. Giraudo et al., "Tie-2-dependent activation of RhoA and Racl participates in endothelial cell motility triggered by angiopoietin-1," Blood, vol. 102, no. 7, pp. 2482-2490, 2003.

[43] B. Witzenbichler, P. C. Maisonpierre, P. Jones, G. D. Yancopoulos, and J. M. Isner, "Chemotactic properties of angiopoietin1 and -2 , ligands for the endothelial-specific receptor tyrosine kinase Tie2," The Journal of Biological Chemistry, vol. 273, no. 29, pp. 18514-18521, 1998.

[44] C. A. Staton, M. W. R. Reed, and N. J. Brown, "A critical analysis of current in vitro and in vivo angiogenesis assays," International Journal of Experimental Pathology, vol. 90, no. 3, pp. 195-221, 2009.

[45] E. Fagiani and G. Christofori, "Angiopoietins in angiogenesis," Cancer Letters, vol. 328, no. 1, pp. 18-26, 2013. 

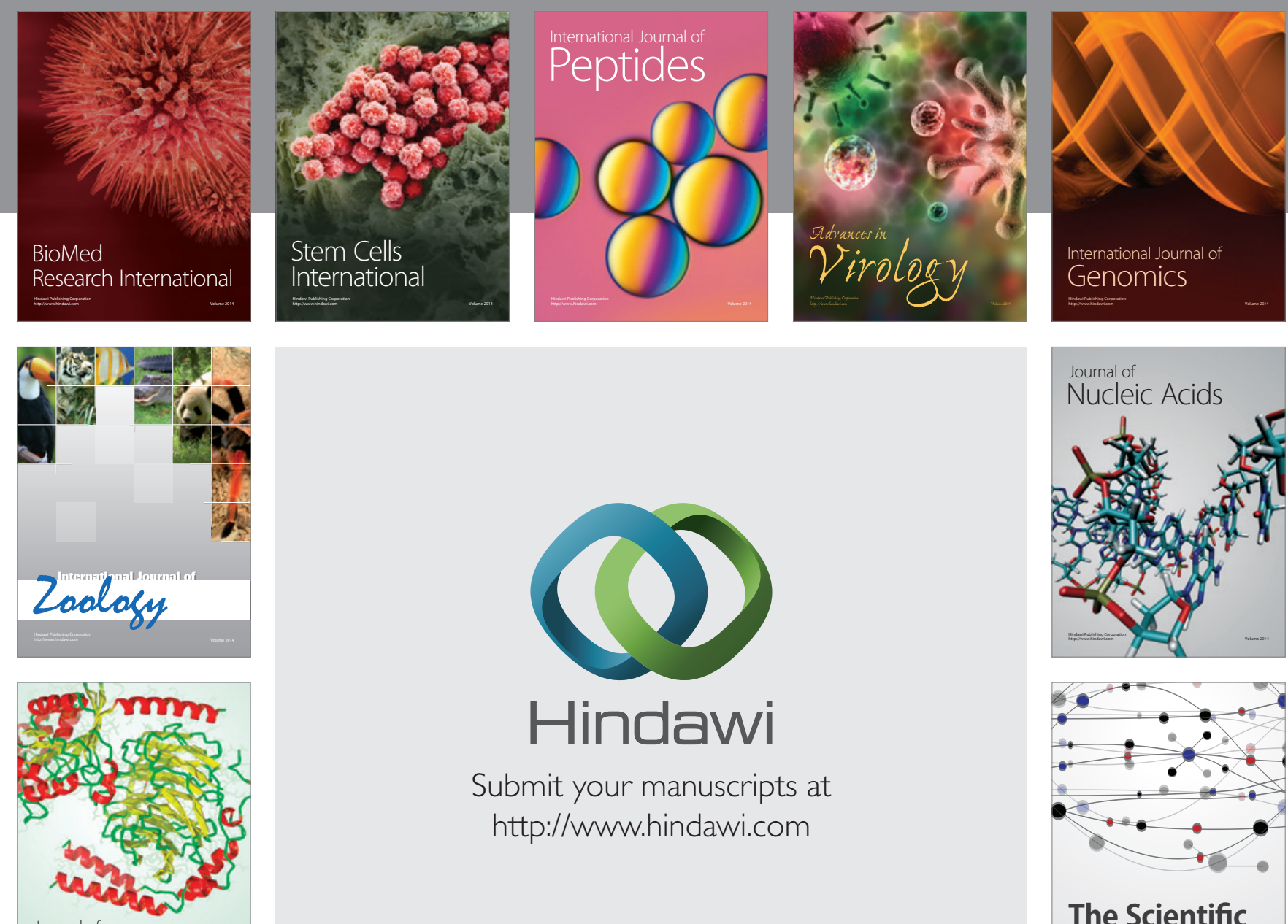

Submit your manuscripts at

http://www.hindawi.com

Journal of
Signal Transduction
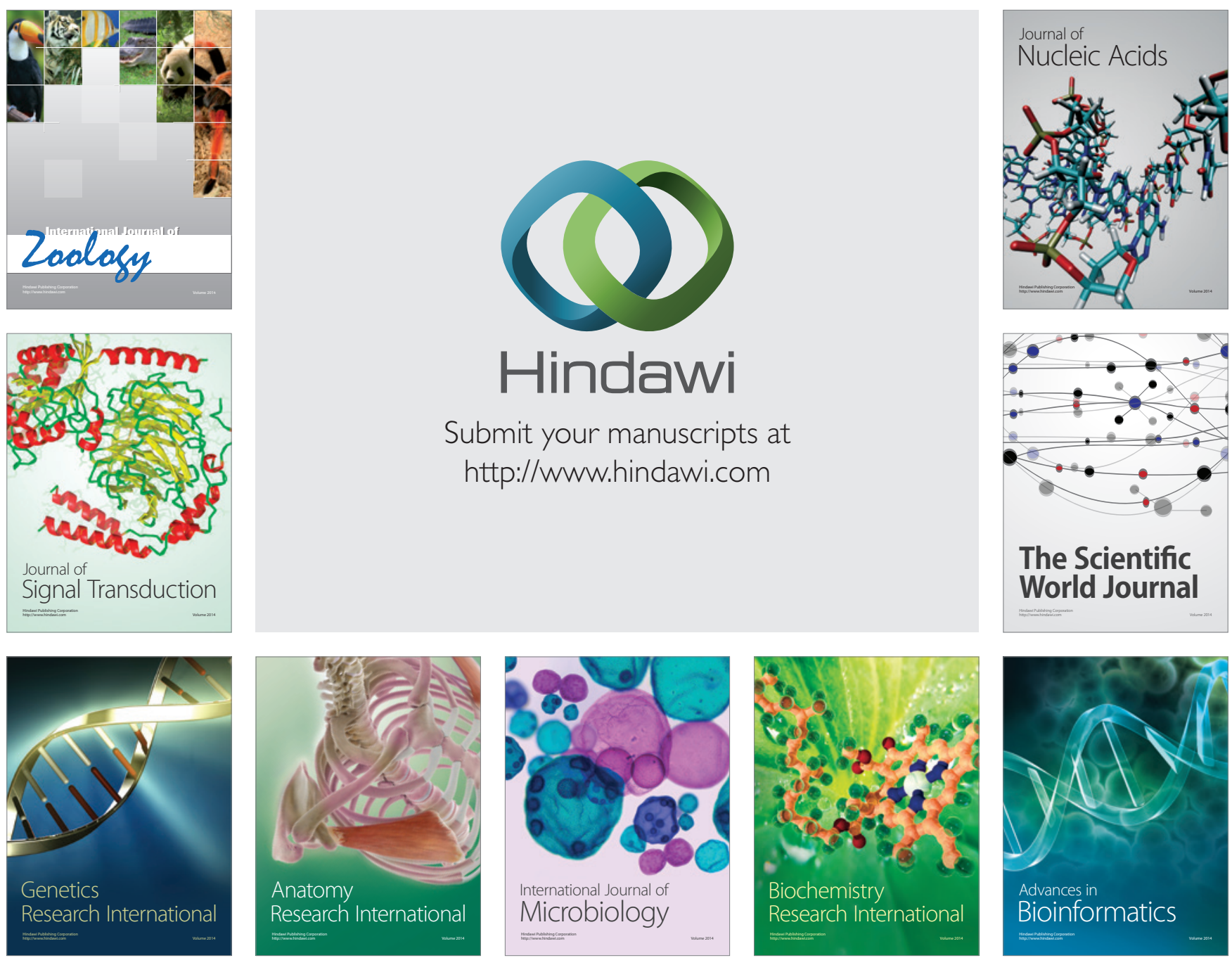

The Scientific World Journal
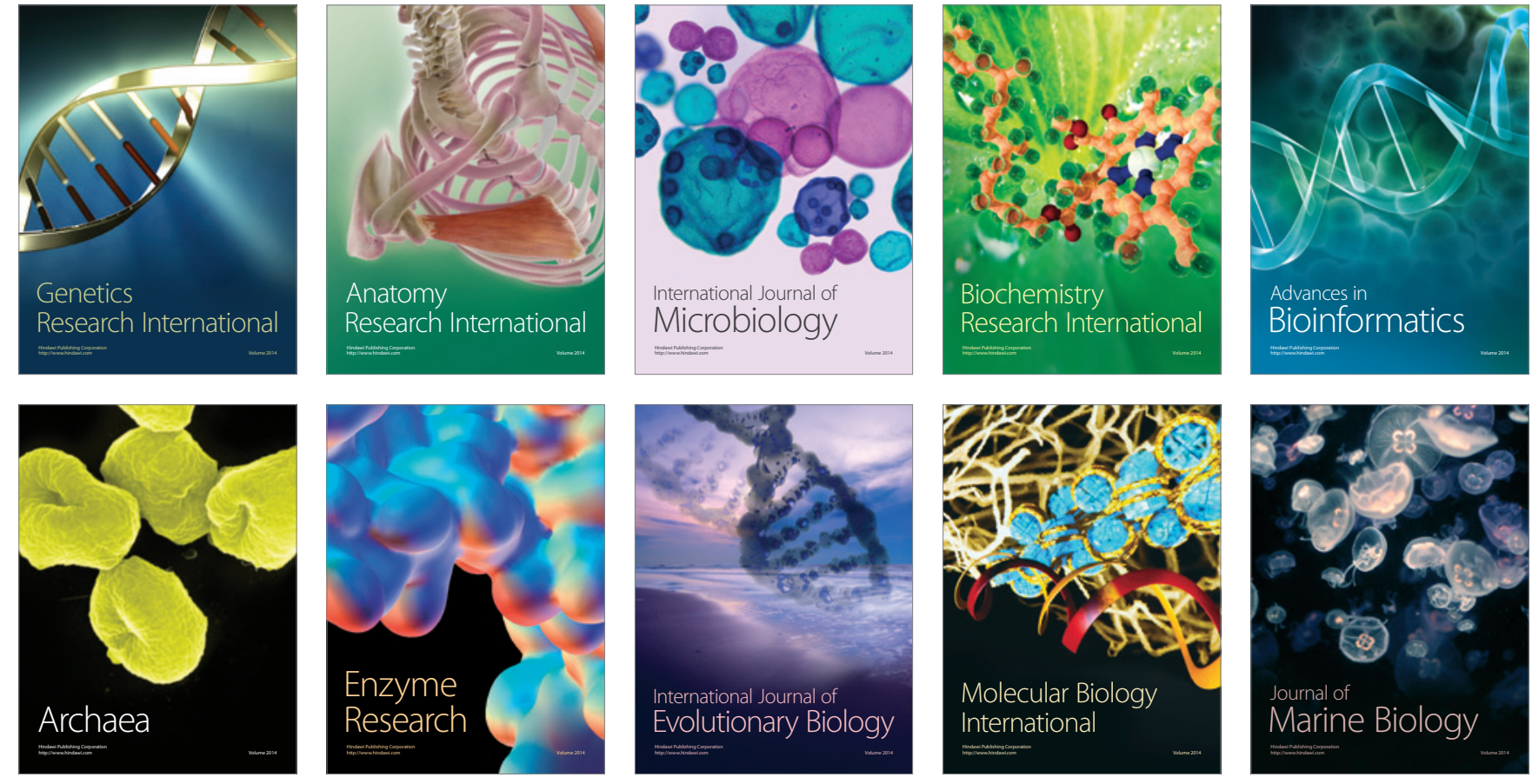